\title{
Article \\ Population Dynamics and Yeast Diversity in Early \\ Winemaking Stages without Sulfites Revealed by Three Complementary Approaches
}

\author{
Sara Windholtz ${ }^{1, *} \mathbb{0}$, Lucie Dutilh ${ }^{2}$, Marine Lucas ${ }^{2}$, Julie Maupeu ${ }^{2} \mathbb{D}$, Amélie Vallet-Courbin ${ }^{2}$, Laura Farris ${ }^{1,3}$, \\ Joana Coulon ${ }^{4}$ and Isabelle Masneuf-Pomarède ${ }^{1,3}$ \\ 1 Unité de Recherche Enologie, EA 4577, USC 1366 INRAE, ISVV, University of Bordeaux, Bordeaux INP, \\ F33882 Villenave d'Ornon, France; laura.farris@agro-bordeaux.fr (L.F.); \\ isabelle.masneuf@agro-bordeaux.fr (I.M.-P.) \\ 2 Microflora-ADERA, Unité de Recherche CEnologie, EA 4577, USC 1366 INRAE, ISVV, \\ F33882 Villenave d'Ornon, France; lucie.dutilh@u-bordeaux.fr (L.D.); marine.lucas@u-bordeaux.fr (M.L.); \\ julie.maupeu@u-bordeaux.fr (J.M.); amelie.vallet-courbin@u-bordeaux.fr (A.V.-C.) \\ 3 Bordeaux Sciences Agro, 33170 Gradignan, France \\ 4 Biolaffort, 11 Rue Aristide Bergès, 33270 Floirac, France; joana.coulon@laffort.com \\ * Correspondence: sarawindholtz@gmail.com
}

\section{check for} updates

Citation: Windholtz, S.; Dutilh, L.; Lucas, M.; Maupeu, J.; Vallet-Courbin, A.; Farris, L.; Coulon, J.;

Masneuf-Pomarède, I. Population Dynamics and Yeast Diversity in Early Winemaking Stages without Sulfites Revealed by Three Complementary Approaches. Appl. Sci. 2021, 11, 2494. https://doi.org/ 10.3390/app11062494

Academic Editor: Guillaume Antalick

Received: 10 February 2021

Accepted: 8 March 2021

Published: 11 March 2021

Publisher's Note: MDPI stays neutral with regard to jurisdictional claims in published maps and institutional affiliations.

Copyright: (c) 2021 by the authors. Licensee MDPI, Basel, Switzerland. This article is an open access article distributed under the terms and conditions of the Creative Commons Attribution (CC BY) license (https:// creativecommons.org/licenses/by/ $4.0 /)$.
Abstract: Nowadays, the use of sulfur dioxide $\left(\mathrm{SO}_{2}\right)$ during the winemaking process is a controversial societal issue. In order to reduce its use, various alternatives are emerging, in particular bioprotection by adding yeasts, with different impacts on yeast microbiota in early winemaking stages. In this study, quantitative-PCR and metabarcoding high-throughput sequencing (HTS) were combined with MALDI-TOF-MS to monitor yeast population dynamic and diversity in the early stages of red winemaking process without sulfites and with bioprotection by Torulaspora delbrueckii and Metschnikowia pulcherrima addition. By using standard procedures for yeast protein extraction and a laboratory-specific database of wine yeasts, identification at species level of $95 \%$ of the isolates was successfully achieved by MALDI-TOF-MS, thus confirming that it is a promising method for wine yeast identification. The different approaches confirmed the implantation and the niche occupation of bioprotection leading to the decrease of fungal communities (HTS) and Hanseniaspora uvarum cultivable population (MALDI-TOF MS). Yeast and fungi diversity was impacted by stage of maceration and, to a lesser extent, by bioprotection and $\mathrm{SO}_{2}$, resulting in a modification of the nature and abundance of the operational taxonomic units (OTUs) diversity.

Keywords: MALDI-TOF MS; oenological laboratory specific database; winemaking without $\mathrm{SO}_{2}$; bioprotection; metabarcoding HTS; quantitative-PCR

\section{Introduction}

Yeast microbiota on the grape berry surface is the main source of the fermentative microbial community responsible for alcoholic fermentation and organoleptic quality of wine. Numerous studies have been carried out to characterize the yeast microbiota during the fermentation process. Different environmental factors (vintage, climate) [1] and technical parameters (temperature, carbon dioxide, inoculation with starters) can impact fungal diversity and population dynamics in grape must during the prefermentary stage [2-4] and alcoholic fermentation [5-7]. Previous studies reported the impact of sulfur dioxide addition on wine microbial diversity [1,8-10] and the yeast population dynamic during alcoholic fermentation [11-13]. More recently, the impact of bioprotection, as an alternative to sulfites, on the microbial characteristics of wines has also been considered [14,15].

Different methods based on culture-independent approaches are available to study yeast microbiota from grapes to wine, such as quantitative-PCR (Q-PCR) and high-throughput 
sequencing (HTS). The Q-PCR method allows the population dynamics of targeted microorganisms to be analyzed, and was applied to characterize the must and wine microbial community [6,7], and to study the impact of non-Saccharomyces on wine quality [16] or the effect of oenological practices on grape must microbial populations [17].

High-throughput sequencing (HTS) methods allow relative abundance and biodiversity indices to be calculated from the sequences obtained. The HTS method has already been developed in oenology [18] using the 454 pyrosequencing method to study the microbial ecology of grape berries or in wine $[19,20]$. However, this latter technology is no longer used and has now been surpassed by Illumina [21].

Traditionally, sequencing analysis of the internal transcribed spacer and 26S rDNA was used for yeast colonies identification at species level. For many years, matrix assisted laser desorption ionization-time of flight mass spectrometry (MALDI-TOF MS) has replaced phenotypic or genetic sequencing identification techniques in the medical environment to become a routine analysis technique $[22,23]$. It is a fast, simple, accurate, and costefficient tool for the identification of microorganisms [24]. Furthermore, beverage sectors such as the beer industry have implemented this method for the identification of spoilage microorganisms or fermentative yeasts [25-27]. Cells are co-crystallized with the matrix in a way that yields a sufficient number of medium-sized ions in the mass spectra. The identification of microbiological samples by this method relies on the acquisition of mass fingerprints and subsequent comparison with a Biotyper database.

In oenology, several studies have aimed to optimize protein extraction protocols, improve yeast identification by creating specific wine microorganism databases [28], or obtain finer identification by the extraction of high mass range moieties [29]. MALDI-TOF MS Biotyper has been used to differentiate oenological yeast at the genus or species level, such as Saccharomyces [30], to identify different groups of Saccharomyces cerevisiae [31,32], and to describe the grape berry microbiota [33]. However, it has been applied little until now for describing the yeast diversity of a must or wine-related environment, and some wine yeast species have not yet been identified due to their absence from the Biotyper database [34].

Today, societal demand tends to reduce chemical inputs in the food industry, with no exception in oenology. Indeed, sulfur dioxide $\left(\mathrm{SO}_{2}\right)$ is particularly targeted as the most used chemical input for winemaking. Microbiological alternatives have emerged, such as "bioprotection". The term "bioprotection" refers to the use of microorganisms or their metabolites to inhibit or even eliminate unwanted microorganisms in foods in order to guarantee hygienic qualities of the products and thus increase their shelf-life without altering their sensory properties $[35,36]$. In oenology, bioprotection is particularly used during prefermentary phase and till now, only pure culture of non-Saccharomyces species was considered [14,15].

The aim of this study was to evaluate a mix of two non-Saccharomyces yeasts as bioprotection (Torulaspora delbrueckii and Metschnikowia pulcherrima) during the prefermentary stages without sulfur dioxide addition at the industrial scale. The MALDI-TOF MS Biotyper analysis was used to study the yeast community diversity during the prefermentary stages and to monitor the implantation of both non-Saccharomyces yeasts used as bioprotection. In a first step, the existing Biotyper database was extended to a laboratory-specific database made with 17 additional new species specific to the wine environment (in total, 43 yeast strains). In parallel to MALDI-TOF MS, two complementary approaches were applied: Q-PCR to monitor population levels of targeted species, and HTS metabarcoding to analyze fungi diversity.

\section{Materials and Methods}

\subsection{Yeast Isolation Procedure}

Yeasts growing were assessed using a specific YPG-based medium $(10 \mathrm{~g} / \mathrm{L}$ Yeast extract, $10 \mathrm{~g} / \mathrm{L}$ Peptone, $20 \mathrm{~g} / \mathrm{L}$ Glucose, and $25 \mathrm{~g} / \mathrm{L}$ agar, $\mathrm{pH}$ adjusted to 4.8 with orthophosphoric acid) named LT (supplemented with $0.15 \mathrm{~g} / \mathrm{L}$ biphenyl (Fluka, Paris, France) 
and $0.1 \mathrm{~g} / \mathrm{L}$ chloramphenicol (Sigma Aldrich, Saint-Quentin Fallavier, France)) to inhibit mold development and bacterial growth, respectively. Samples were spread at tenfold serial dilution in triplicate and incubated under aerobic conditions at $26{ }^{\circ} \mathrm{C}$ for 5 days. Plates containing between 30 and 300 colonies were counted, and colony-forming units (CFU) per $\mathrm{mL}$ were recorded and type of colony enumerated. For samples at prefermentary stages and start of alcoholic fermentation, around 30 colonies were picked according to the proportion of each type of colony and plated onto fresh LT plates.

\subsection{MALDI-TOF MS}

\subsubsection{Validation of Yeast Identification by MALDI-TOF MS Biotyper}

Biological material from a freshly-grown single colony was used in parallel for identification at species level (i) by sequencing 26S rDNA using NL1-NL4 primers for amplification [37] and (ii) by MALDI-TOF MS Biotyper. For MALDI-TOF MS analysis, a fresh colony was spotted onto an MSP 96 target polished steel BC (Bruker, Karlsruhe, Germany) and allowed to dry at room temperature. The spot of each colony was overlaid with $1 \mu \mathrm{L}$ $70 \%$ formic acid and dried at room temperature. All the samples were overlaid with $\alpha$ cyano-4-hydroxycinamic acid (HCCA) $(1 \mu \mathrm{L})$ matrix (Bruker, Germany) for crystallization. MALDI-TOF MS analysis was performed on a Microflex ${ }^{\mathrm{TM}}$ LT/SH MALDI-MS System (Bruker Daltonics, Bremen, Germany) using Flex Control (Version 3.1), MTB Compass (Version 3.1) (Bruker Daltonics, Bremen, Germany), and MALDI-Biotyper ${ }^{\mathrm{TM}}$ application (Bruker Daltonics, Bremen, Germany), which allows the similarity of the mass profile of an unknown microorganism to be calculated with the mass profiles in a database. To calibrate the mass spectral data generated by the instrument, the Bruker bacterial test standard (BTS) (Bruker, Germany) was added to each plate as a control. The identification of microbiological samples by this method relies on the acquisition of mass fingerprints and subsequent comparison of the data with the Biotyper database. The spectra were analyzed in an $\mathrm{m} / \mathrm{z}$ of 2 to $20 \mathrm{kDa}$ [38]. Results of the pattern-matching process were expressed as proposed by the manufacturer, with scores ranging from 0 to 3 . Scores $>2.3$ indicated highly probable species identification, score values between 1.7 and 2.0 generally indicated relationships at genus level, and a score $<1.7$ indicated that the identification was not reliable $[39,40]$.

\subsubsection{MALDI-TOF MS Oenological Laboratory Specific Database (OLS-DB)}

The yeast strains chosen to enhance the new laboratory specific database, provided by CRB Oeno (centre de Ressources Biologiques, Unité de Recherche Oenologie, Villenave d'Ornon, France), are listed in Appendix A Table A1. These strains were previously identified by sequencing of $26 \mathrm{~S}$ rDNA using NL1-NL4 primers [37] (Table A1). An oenological microorganism mass profiles database was created with the MTB Compass Explorer Module (Version 4.1) and Flex Analysis (Version 3.4) (Bruker Daltonics, Bremen, Germany) as follows. A complete extraction was carried out for each strain added to the database. The strains were grown and subcloned on YPG medium. For each isolate, yeast protein extraction was carried out in duplicate in order to generate the reference MALDI-TOF MS spectra for a given strain.

For yeast protein extraction, one fresh colony of each previously-purified isolate was transferred into an Eppendorf tube containing $300 \mu \mathrm{L}$ of High Performance Liquid Chromatography (HPLC) quality water (VWR Prolabo, Fontenay-sous-bois, France), and a cloudy suspension was obtained after stirring. A total of $900 \mu \mathrm{L}$ of absolute ethanol (VWR Prolabo, Fontenay-sous-bois, France) was added and then centrifuged at 13,000-15,000 rpm for $2 \mathrm{~min}$. The supernatant was removed, and the resulting pellet was allowed to air dry at room temperature for $5 \mathrm{~min}$. A total of $25 \mu \mathrm{L}$ of $70 \%$ formic acid was added and mixed using a pipette until the pellet was completely dissolved, then $25 \mu \mathrm{L}$ of $100 \%$ acetonitrile (VWR Prolabo, Fontenay-sous-bois, France) was added and all vortexed. Finally, the mixture was centrifuged for $2 \mathrm{~min}$ at 13,000-15,000 rpm and $1 \mu \mathrm{L}$ of the supernatant was deposited onto an MSP 96 target polished steel BC (Bruker, Germany) and allowed to dry at room temperature. All the samples were overlaid with HCCA $(1 \mu \mathrm{L})$ matrix for crystallization. 
For a given strain, four separate deposits from each of the two protein extractions were distributed on the plate. These eight deposits allowed 24 MALDI-TOF MS spectra to be obtained per strain. A baseline check was then performed for each of the 24 spectra, which were compared in pairs: this allowed the homogeneity of the spectra for a given strain to be assessed. The 70 most intense peaks of all spectra of each strain were listed, taking their frequency of occurrence into account.

\subsection{Red Wine Vinification Process and Sampling}

The trial was carried out in 2018 with Merlot N. (Vitis vinifera L.) grapes from vineyards located in the Pomerol region of Bordeaux, France. Grapes were harvested manually from the same plot in small crates, at optimal ripening stage and sanitary status. Clusters were separated into three batches according to the following treatments: bioprotection (BP), $\mathrm{SO}_{2}$ at $50 \mathrm{mg} / \mathrm{L}$, and without $\mathrm{SO}_{2}(0) . \mathrm{SO}_{2}$ was added at vatting in the form of potassium metabisulfite (KMS). Bioprotection was composed of a mixture of two species, Torulaspora delbrueckii and Metschnikowia pulcherrima (Zymaflore ${ }^{\circledR}$ Egide-Laffort, Floirac, France), and was applied directly to the grapes at $50 \mathrm{~m} / \mathrm{L}$ following the manufacturer's protocol and without addition of $\mathrm{SO}_{2}$. In the winery, the harvest was crushed according to standard practice and distributed between new $225 \mathrm{~L}$ French oak barrels. Prefermentary maceration was carried out at $13{ }^{\circ} \mathrm{C}$ before inoculation $(200 \mathrm{mg} / \mathrm{L})$ with a commercial active dry yeast (ADY) Saccharomyces cerevisiae after $48 \mathrm{~h}$. Each treatment was duplicated. During the prefermentary maceration, $10 \mathrm{~mL}$ of must were sampled in sterile conditions at different stages for each barrel: vatting, $24 \mathrm{~h}$ of maceration, $48 \mathrm{~h}$ of maceration, and start of alcoholic fermentation. Samples were transported to the laboratory immediately on ice for processing.

\subsection{Yeast and Fungi Community Analysis}

\subsubsection{DNA Extraction}

The cells were collected from samples after centrifuging at $9000 \mathrm{rpm}$ during $10 \mathrm{~min}$ and were rinsed twice with EDTA $50 \mathrm{mM}$ before being frozen and conserved at $-20^{\circ} \mathrm{C}$ until subsequent DNA extraction. For DNA extraction, the protocol was followed according to Zott et al. (2010). DNAs were conserved at $-20^{\circ} \mathrm{C}$.

\subsubsection{Population Dynamics of Targeted Microorganisms by Quantitative PCR}

The Q-PCR method was chosen to monitor the population levels of different species and target communities using specific primers (Table A2): Torulaspora delbrueckii, Metschnikowia pulcherrima, and Hanseniaspora sp.

The Q-PCR program was one 5-min cycle at $95^{\circ} \mathrm{C}$, followed by 40 cycles at $95^{\circ} \mathrm{C}$ for $10 \mathrm{~s}, 60-63^{\circ} \mathrm{C}$ (differed according to primer pairs) for $30 \mathrm{~s}$, and $72{ }^{\circ} \mathrm{C}$ for $30 \mathrm{~s}$, completed by the post-PCR. To obtain the melting temperature, the temperature was increased by $0.3^{\circ} \mathrm{C}$ every $10 \mathrm{~s}$ from $63{ }^{\circ} \mathrm{C}$ to $95^{\circ} \mathrm{C}$ for each specific Q-PCR. Samples for $20 \mu \mathrm{L}$ reactions were prepared as described by Zott et al. (2010). For each sample, four amplifications were considered: DNA extract and DNA diluted per 10, both in duplicate. Standard curves were built for each yeast species in triplicate, using DNA extracted from 10-fold serial dilutions of fresh cultures in pasteurized red must.

\subsubsection{Yeast Biodiversity Analysis}

- Meta-barcoding and high-throughput sequencing analysis (HTS)

HTS analysis targeting rDNA $18 \mathrm{~S}$ (fungal) was applied to all samples. DNA libraries for fungi were prepared according to the following protocol: a 350 base (on average) $18 \mathrm{~S}$ rDNA gene fragment was amplified from each DNA sample with the universal primers FR1 (Amplicon PCR Reverse Primer overhang adapter $=5^{\prime}$ GTCTCGTGGGCTCGGAGATGT GTATAAGAGACAANCCATTCAATC GGTANT) and FF390 (Amplicon PCR Forward Primer overhang adapter $=5^{\prime}$ TCGTCGGCAGCGTCAGATGTGTATAAGAGACAGCG ATAACGAACGAGACCT [19]. This first PCR targeting regions with specific primers 
including universal sequence primers (amplicon PCR primers) was performed in the laboratory. PCR reactions consisted of $2.5 \mu \mathrm{L}$ of dilute template (DNAs standardized to $5 \mathrm{ng} / \mu \mathrm{L}), 5 \mu \mathrm{L}$ of each Amplicon PCR Primer $1 \mu \mathrm{M}, 12.5 \mu \mathrm{L} 2$ X KAPA HiFi HotStart Ready Mix (Roche, Basel, Switzerland). Reactions were cycled for 3 min at $95^{\circ} \mathrm{C}$, then for 35 cycles of $98^{\circ} \mathrm{C}$ for $30 \mathrm{~s}, 52{ }^{\circ} \mathrm{C}$ for $30 \mathrm{~s}$, and $72{ }^{\circ} \mathrm{C}$ for $60 \mathrm{~s}$, then followed by a final extension period of 8 min at $72{ }^{\circ} \mathrm{C}$.

The second PCR consisted of attaching indices and Illumina sequencing adapters using the Nextera ${ }^{\circledR}$ XT Index Kit (Juno Beach, FL, USA), made by Plateforme GenomeTranscriptome in Bordeaux. Finally, normalized pool libraries for the Illumina paired-end library were prepared, and cluster generation and $2 \times 250 \mathrm{bp}$ paired-end sequencing (MiSeq Kit NANO v2) were performed on an Illumina MiSeq instrument.

Data were subsequently imported into the Find Rapidly OTUs with Galaxy Solution (FROGS) Pipeline [41]. The sequences were cleaned as follows. Preprocess: paired-end assembled, with $5^{\prime}$ primer, with $3^{\prime}$ primer, with expected length ( $<300$ and $>400$ bps), and without $\mathrm{N}$. Then, sequences were dereplicated before being clustered using SWARM [42] with a local clustering threshold with a distance of 3 . This single-link method is robust and independent of the sequence at which it is begun. Chimeras were removed with vsearch [43]: chimeras are sequences formed from two or more biological sequences joined together. The resulting sequences were filtered to remove singletons, using Filter phiX (contaminant databank). Taxonomic assignment of operational taxonomic units (OTUs) corresponding to $18 \mathrm{~S}$ rDNA sequences was performed using silva132 18S [44] as the reference database. Sequences were filtered on BLAST with a percentage of identity (97\%) and percentage of coverage (95\%). An affiliation postprocess allowed inclusive amplicon ambiguities to be resolved and OTUs aggregated based on alignment metrics. Finally, OTUs corresponding to Vitis sp. were removed.

- Yeast diversity analysis by MALDI-TOF MS

Total yeast population was quantified by the plating method on LT medium. The identification of 30 clones per sample was performed at species level following the manufacturer's protocol (Bruker, Germany) as previously described and using the oenological laboratory specific database.

\subsection{Statistical Analysis}

The $\alpha$-diversity was calculated by using R package phyloseq [45] from the OTU matrix generated by FROGS as input [41]. "Observed" concerns the number of OTUs; "Chao1" estimate the number of unobserved species from those observed one or two times. Shannon and Inverse Simpson are quantitative index; it takes into account the abundance of each OTUs.

The data were assumed to be normally distributed (Shapiro-Wilks normality test, $p>0.05$ ) and the variance homogeneity was verified (Leven test, $p>0.05$ ). The data were then analyzed by single-factor variance analysis (ANOVA, $p<0.05$ ) and the normal distribution of the residual data was verified (Shapiro-Wilks normality test, $p>0.05$ ). All tests were carried out using the R Studio program.

\section{Results}

\subsection{Optimization of Wine Yeast Identification by MALDI-TOF MS}

3.1.1. Comparative Analysis of Species Identification by MALDI-TOF MS Biotyper Database and 26S rDNA Sequencing

In a first study, 623 yeast clones isolated from the prefermentary stages and beginning of alcoholic fermentation were first identified using $26 \mathrm{~S}$ rDNA sequencing. All the yeast isolates were identified successfully by sequencing at species level, resulting in 17 yeast species among traditional oenological ones (Figure 1). A majority of the yeast isolates $(66 \%)$ were identified correctly at species level (score $>2$ ) by the MALDI-TOF MS with Biotyper database and according to the $26 \mathrm{~S}$ rDNA sequencing identification, whereas $6 \%$ were identified only at genus level (score between $1.8-2$ ). Finally, $28 \%$ of yeast isolates were not 
identified (176 clones out of 623) using the MALDI-TOF MS Biotyper database, probably because the colony extraction and/or identification scores were not correct. Although the S. cerevisiae species is well represented in the Biotyper database (13 strains), only $54 \%$ of isolates identified by $26 \mathrm{~S}$ rDNA sequencing (191/353 clones) were correctly identified using the MALDI-TOF MS Biotyper database (score $>2$ ) (Figure 1). For the 162 S. cerevisiae isolates not correctly identified by the MALDI-TOF MS Biotyper database, the scores were lower than 1.8 (134 isolates), probably due to the non-wine origin of the S. cerevisiae in the Biotyper database. For $H$. uvarum, representing $20 \%$ of the isolates by $26 \mathrm{~S}$ rDNA sequencing, $90 \%$ of total H. uvarum isolates were identified correctly by the MALDI-TOF MS Biotyper database that contains eight strains.

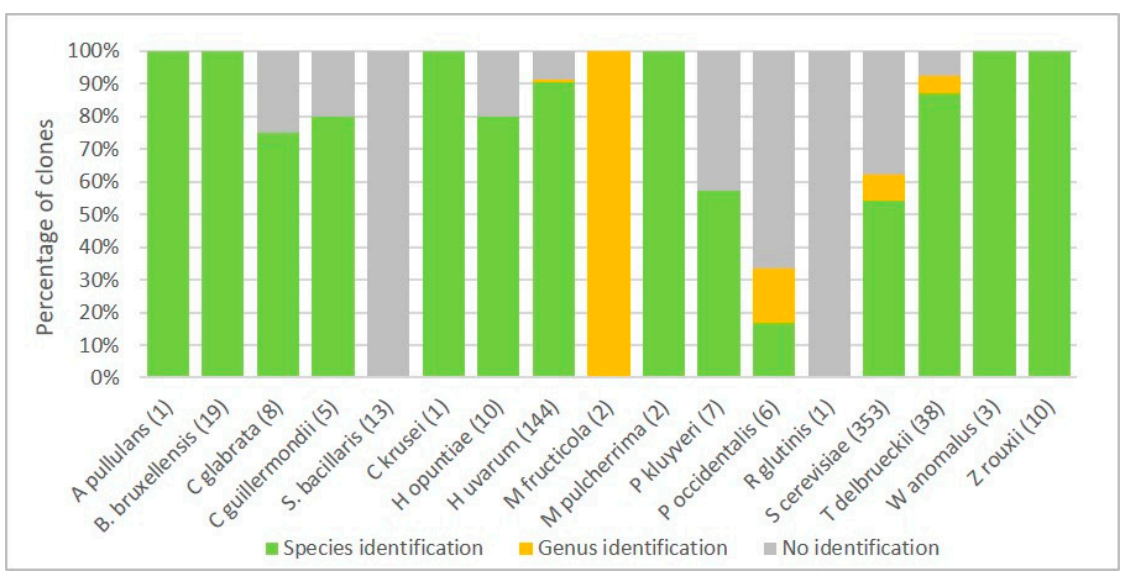

Figure 1. Percentage of clones given identical identification by $26 \mathrm{~S}$ rDNA sequencing and MALDITOF MS (the number of clones considered is given in brackets).

\subsubsection{Oenological Laboratory Specific Database of MALDI-TOF MS}

The oenological laboratory specific Biotyper database was created with yeast species and strains specific to the wine environment. Yeast strains originating from must and wine were provided by CRB OENO. For all isolates, species identification was validated by $26 \mathrm{~S}$ rDNA sequencing, and the sequence and match information on BLAST are presented as Table A1. To implement the database, different situations were considered: (i) when strains of a given species were present in the Bruker database and its identification result was $<2.0$, only one or two strains isolated from the wine environment were approved in the database (as for example for Hanseniaspora uvarum or Lachancea thermotolerans), (ii) when species were not present in the database (Shizosaccharomyces japonicus or Starmerella bacillaris), only one or two strains were added, leading to an identification score $>2$.

For Saccharomyces cerevisiae, the scores with wine isolates were not correct $(<2.0)$, and five additional $S$. cerevisiae strains originating from a wine environment were therefore added, and the resulting identification scores were found to be greater than 2 using these two databases. For Pichia guilliermondii, 14 strains were already present in the Biotyper database, while the identification results were $>2.0$ for wine isolates; only one strain of Pichia guilliermondii related to the wine environment was added. Considering the genetic and phenotypic diversity of Brettanomyces bruxellensis [46], 15 strains representative of the genetic groups of the species were added. Finally, 17 distinct species and 43 different strains were added to the existing database (Table 1). 
Table 1. Numbers of strains per species in the Biotyper database (Biotyper DB) and the oenological laboratory specific database (OLS DB).

\begin{tabular}{cccc}
\hline Genus & Species & $\begin{array}{c}\text { Number of Strains in } \\
\text { Biotyper DB }\end{array}$ & $\begin{array}{c}\text { Number of Strains in } \\
\text { OLS DB }\end{array}$ \\
\hline Aureobasidium & pullulans & 3 & 2 \\
Brettanomyces & acidodurans & 0 & 1 \\
Brettanomyces & bruxellensis & 5 & 15 \\
Candida & cantarelli & 0 & 2 \\
Starmerella & bacillaris & 0 & 2 \\
Hanseniaspora & uvarum & 8 & 2 \\
Lanchancea & thermotolerans & 3 & 1 \\
Metschnikowia & pulcherima & 4 & 2 \\
Pichia (Candida) & guiliermondii & 14 & 1 \\
Pichia & kluyveri & 1 & 1 \\
Pichia (Candida) & membranifaciens & 2 & 1 \\
Saccharomyces & cerevisiae & 13 & 5 \\
Shizosaccharomyces & japonicus & 0 & 1 \\
Shizosaccharomyces & octosporus & 0 & 1 \\
Shizosaccharomyces & pombe & 4 & 3 \\
Torulaspora & delbrueckii & 5 & 2 \\
Zygosaccharomyces & bailii & 3 & 1 \\
\hline
\end{tabular}

\subsection{Yeast and Fungi Community during the Early Stages of Winemaking without Sulfites}

Merlot N. (Vitis vinifera L.) grapes collected in 2018 were separated into three batches according to the following treatments: bioprotection (BP), $\mathrm{SO}_{2}$ at $50 \mathrm{mg} / \mathrm{L}$, and without $\mathrm{SO}_{2}$ (0). Grape must was collected at four different stages (vatting, $24 \mathrm{~h}, 48 \mathrm{~h}$, beginning of alcoholic fermentation), thus resulting in 18 samples for further analysis. Chemical analysis of the Merlot grape must and wine at the end of the alcoholic fermentation are given in Table A3; no significant differences from one modality to another were noticed for grape must enological parameters, except for the total $\mathrm{SO}_{2}$ that was logically higher for the $\mathrm{SO}_{2}$ modality comparing with bioprotection and without $\mathrm{SO}_{2}$ modalities. The wine analysis showed no significant difference concerning the acetic acid content except for the residual sugars for the without sulfites modality (Table A3).

3.2.1. Population Dynamics of Hanseniaspora spp. and Non-Saccharomyces Yeasts Used as Bioprotection

Three yeast species and genera (Torulaspora delbrueckii, Metschnikowia pulcherrima, and Hanseniaspora spp.) were targeted to monitor population dynamics using Q-PCR. Results are given in Figure 2 and Table A4. Population levels of Hanseniaspora sp. were relatively stable during the prefermentary stages, ranging from $2.8 \times 10^{2}$ to $1.2 \times 10^{4}$ cells $/ \mathrm{mL}$, whatever the modality considered, and then increased during the start of the alcoholic fermentation reaching 1.4-1.2 $\times 10^{6}$ cells $/ \mathrm{mL}$. Levels of indigenous populations of Torulaspora delbrueckii and Metschnikowia pulcherrima (with $\mathrm{SO}_{2}$ and without $\mathrm{SO}_{2}$ treatment) were low and below the detection limit of Q-PCR $(<100$ cells $/ \mathrm{mL})$, except for duplicates at the vatting stage without $\mathrm{SO}_{2}$ (Metschnikowia pulcherrima at $3.9 \times 10^{2}$ cells $/ \mathrm{mL}$ and $5.8 \times 10^{2}$ cells $/ \mathrm{mL}$, respectively) and the start of alcoholic fermentation. Population levels of both species inoculated as the bioprotection treatment at the vatting stage confirmed the effective implantation of Torulaspora delbrueckii and Metschnikowia pulcherrima, with averages of $5.7 \times 10^{4}$ and $4.4 \times 10^{6}$ cells $/ \mathrm{mL}$, respectively. Torulaspora delbrueckii population levels were relatively stable during the prefermentary stages, whereas the Metschnikowia pulcherrima population decreased to $3.4 \times 10^{4}$ cells $/ \mathrm{mL}$ on average after $48 \mathrm{~h}$ of maceration and then increased to $1.2 \times 10^{6}$ at the start of alcoholic fermentation. 

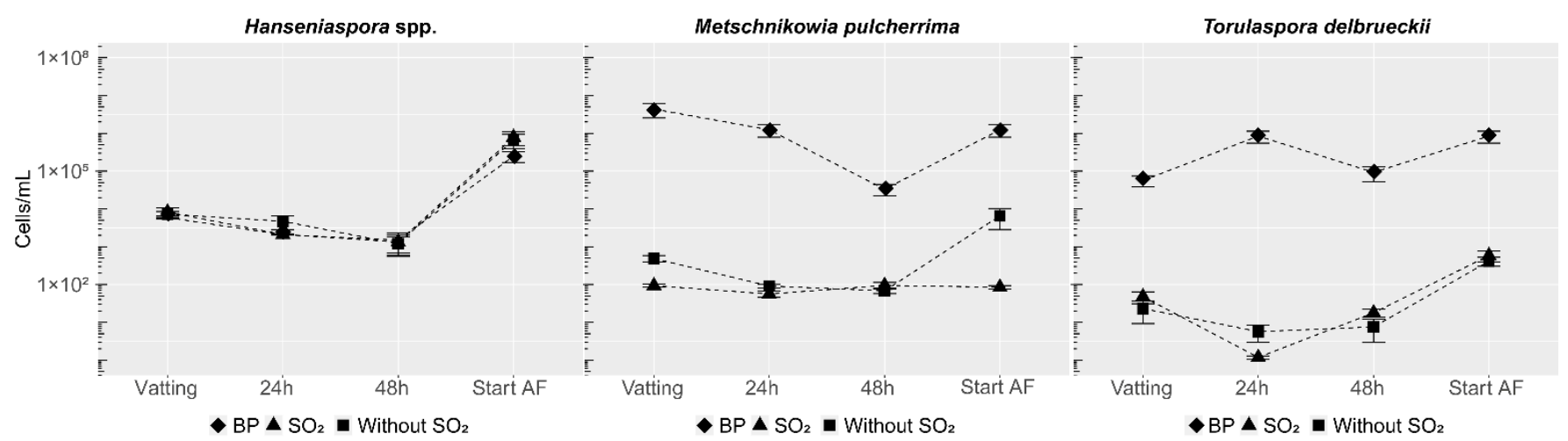

Figure 2. Population dynamics of Hanseniaspora spp., Metschnikowia pulcherrima, and Torulaspora delbrueckii. During prefermentary stages (vatting, $24 \mathrm{~h}$, and $48 \mathrm{~h}$ of maceration, start of alcoholic fermentation). Bioprotection (BP), $\mathrm{SO} 2$, and without $\mathrm{SO}_{2}$ treatments. Values indicated as the mean of four technical replicates \pm standard deviation.

\subsubsection{Yeasts and Fungal Diversity}

HTS of the $18 \mathrm{~S}$ rDNA gene was used to evaluate yeast and fungi microbial diversity during the prefermentary stages. The start of alcoholic fermentation was not considered for HTS due to the inoculation of the yeast with ADY Saccharomyces cerevisiae. A total of 18 samples were sequenced, resulting in 190,016 paired-end reads assembled with $5^{\prime}$ primers, $3^{\prime}$ primers, with expected length (between 300 and $400 \mathrm{bps}$ ), without ambiguous base calls ( $\mathrm{N}$ characters) in their sequence or barcode. After filtering of chimeras, singletons, clustering SWARM and affiliation OTUs, 161,667 sequences were assigned to 493 OTUs. After a blast filter step (for identity and coverage), a preprocess step, and a Vitis sp. removal step $(-17.90 \%), 123$ OTUs with 131,864 sequences were obtained. Finally, 7716 sequences were retained on average for each sample, except for one replicate at $48 \mathrm{~h}$ of maceration (without $\mathrm{SO}_{2}$ treatment) that was deleted because of its low number of sequences (729).

Different phyla were detected among all OTUs, mostly within Ascomycota (95.9\%), followed by Basidiomycota (2.3\%), Cryptomycota (1.6\%), and other phyla, but with an abundance below $1 \%$ of all OTUs (data not shown). The Ascomycota phylum contained 11 classes, including 57.2\% Dothideomycetes (represented by three genera: Aureobasidium (63\%), Cladosporium (28\%); Alternaria (3.4\%)), $25.9 \%$ Saccharomycetes (represented by the Metschnikowia (47.3\%); Torulaspora (46.8\%) and Hanseniaspora (3.2\%) genera) and $12.8 \%$ Leotiomycetes (represented predominantly by the Botrytis genus (99.5\%)) (Table A4).

Among the eight major genera within the Ascomycota phylum (Figure $3 \mathrm{~A}$ and Table A4), five belonged to molds previously reported on the grape berry (Alternaria, Aureobasidium, Cladosporium, Botrytis, and Diplodia) $[47,48]$. The Aureobasidium, Cladosporium, and Botrytis genera were dominant whether the musts were sulfited or not. In accordance with population dynamic results, the Torulaspora and Metschnikowia genera were most abundant for the bioprotection treatment. At the vatting stage, Torulaspora represented $25 \%$ of the total relative abundance and this percentage remained stable during prefermentary maceration. By contrast, Metschnikowia represented approximately $40 \%$ of the total relative abundance and then decreased during maceration (30\%), according to the Q-PCR results. Bioprotection led to a decrease in the relative abundance of Aureobasidium, Botrytis, and Cladosporium in comparison with the other treatments. The use of $\mathrm{SO}_{2}$ at vatting did not lead to any significant changes in the relative abundances obtained from the eight major genera in the samples. Hanseniaspora was poorly represented, ranging from 0.1 to $2.4 \%$ for all samples. Among the percentage of "Others" in Figure 3A, twelve additional genera were represented, with six fungi genera (Aspergillus, Ramularia, Pleospora, Colletotrichum, Taphrina, and Zopfia) and five yeast genera commonly associated with the grape berry microbial community (Kluyveromyces, Candida, Saccharomyces, Lachancea, and Pichia are grape yeasts) (Figure 3B). Surprisingly, the Starmerella bacillaris species was not identified among the sequences. 


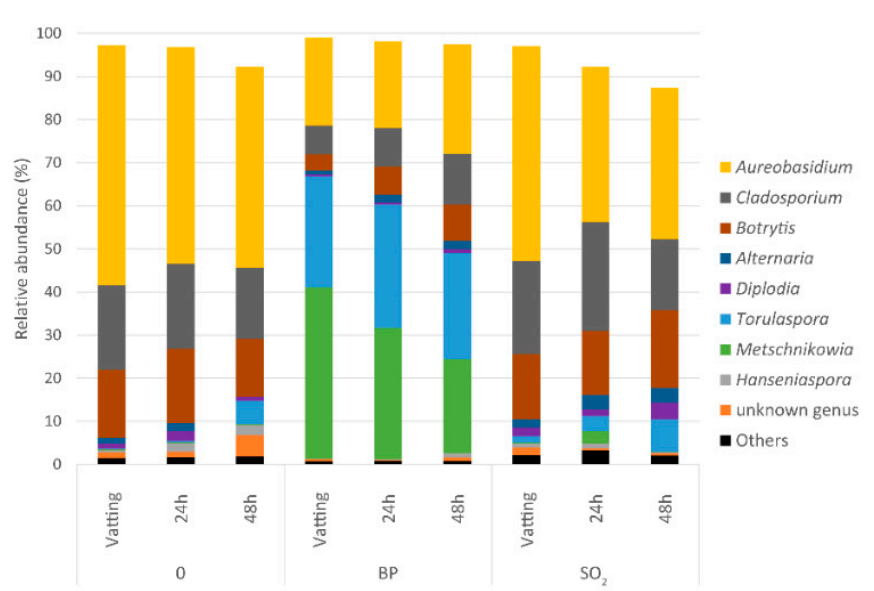

(A)

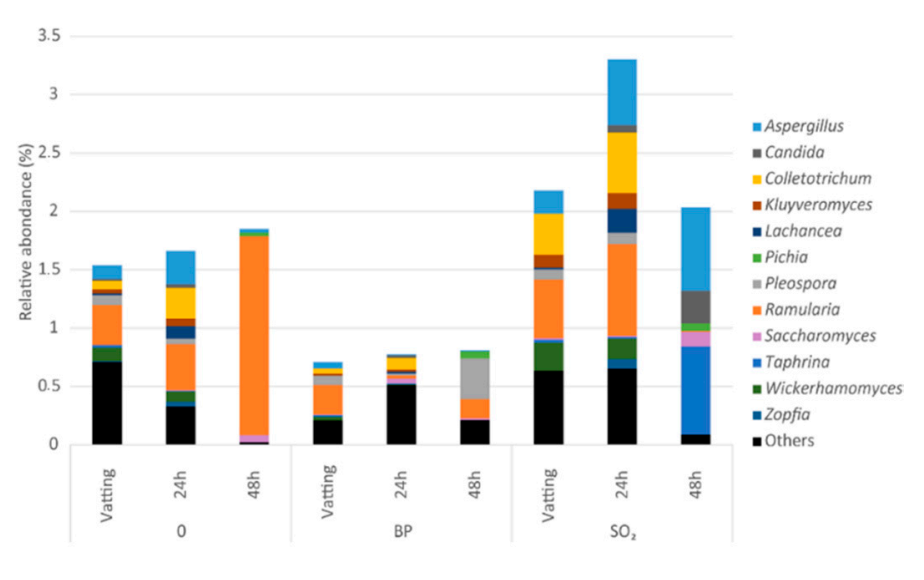

(B)

Figure 3. (A) Relative genus abundances based on the taxonomic assignation of high-quality $18 \mathrm{~S}$ rDNA reads of Ascomycota phylum from must samples at prefermentary stages (treatment: without $\mathrm{SO}_{2}(0), \mathrm{SO}_{2}\left(\mathrm{SO}_{2}\right)$, bioprotection (BP); stages: vatting, $24 \mathrm{~h}$ prefermentary maceration, $48 \mathrm{~h}$ prefermentary maceration). (B) Relative genus abundances in "Others" category for each sample. (Mean of biological replicates).

Biodiversity indices were calculated based on high-throughput sequencing data (Figure 4). The number of OTUs at the vatting stage was significantly lower for the bioprotection treatment compared to the other treatments ( $43 \pm 4$ OTUs versus $60 \pm 3$ OTUs). Overall, the number of observed OTUs decreased and $\alpha$ diversity increased ("Shannon" and "invSimpson" index) during prefermentary maceration, whatever the treatment considered. The drop in the number of observed OTUs was particularly marked for the without $\mathrm{SO}_{2}(0)$ and $\mathrm{SO}_{2}$ treatments. The "Shannon" index and "InvSimpson" index were significantly higher for the $\mathrm{BP}$ and the $\mathrm{SO}_{2}$ treatment than for without $\mathrm{SO}_{2}$ for the first two stages (vatting and $24 \mathrm{~h}$ of maceration $(24 \mathrm{~h})$ ).

Table 2 presents the explained variance by "Stage" (vatting, $24 \mathrm{~h}$ and $48 \mathrm{~h}$ of maceration) and "Treatment" (BP, $\left.0, \mathrm{SO}_{2}\right)$ factor and the combination of the two factors for biodiversity indices. The "Stage" factor accounted for the higher percentage of variance (ANOVA $p<0.05$ ) for all the biodiversity indices and explained $50 \%$ of the variance on average. "Treatment" significantly impacted the number "Observed" and the "InvSimpson" index. The interaction between these two parameters did not show any significant impact whatever the biodiversity index considered.

Table 2. Percentage of variance explained by treatment and stage factors for different biodiversity indices (significance codes for $p$ value: ${ }^{* *} 0.01$ and ${ }^{*} 0.05$ ).

\begin{tabular}{ccccc}
\hline & Observed & Chao1 & Shannon & InvSimpson \\
\hline Stage & $52.70 \%^{* *}$ & $53.29 \%^{* *}$ & $44.90 \%{ }^{*}$ & $53.96 \% \%^{* *}$ \\
Treatment & $19.13 \%^{*}$ & $11.25 \%$ & $13.77 \%$ & $22.79 \%^{*}$ \\
Treatment ${ }^{*}$ Stage & $14.48 \%$ & $19.67 \%$ & $4.90 \%$ & $6.19 \%$ \\
Residuals & $13.64 \%$ & $15.78 \%$ & $36.33 \%$ & $17.05 \%$ \\
\hline
\end{tabular}

MALDI-TOF-MS was applied on yeast isolates from samples collected during prefermentary stages and start of alcoholic fermentation. 


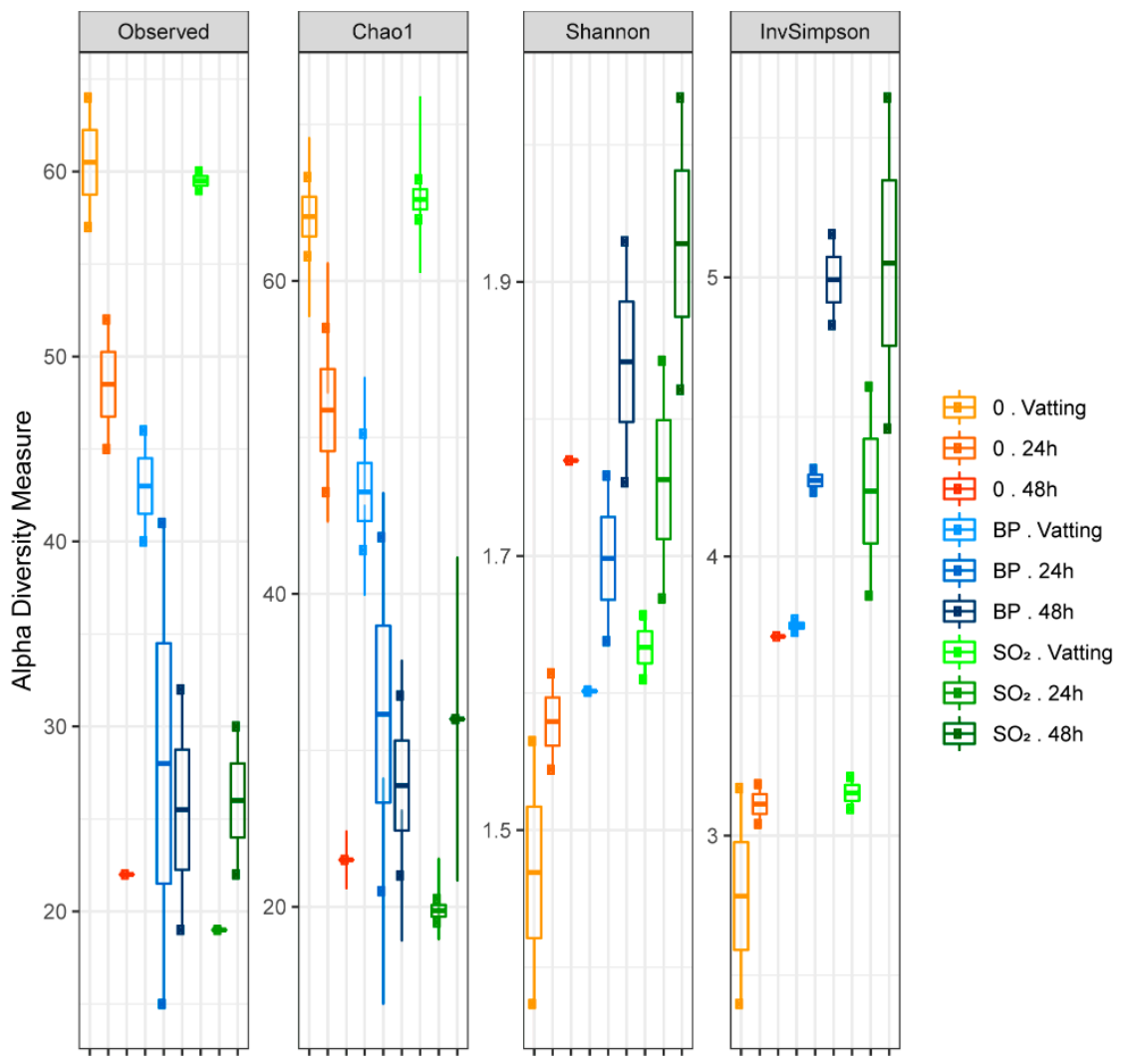

Figure 4. Boxplot of $\alpha$ diversity by four indices based on the taxonomic assignation of high-quality $18 \mathrm{~S}$ rDNA reads of fungi from must samples at prefermentary stages (treatment: without $\mathrm{SO}_{2}(0)$, $\mathrm{SO}_{2}\left(\mathrm{SO}_{2}\right)$, bioprotection (BP); stages: vatting, $24 \mathrm{~h}$, and $48 \mathrm{~h}$ prefermentary maceration.

Levels of the total yeast population by plating method on LT medium are given in Table A4. Total yeast populations were from $8.3 \times 10^{2}$ to $2.3 \times 10^{3} \mathrm{CFU} / \mathrm{mL}$ for the vatting stage, except for the bioprotection treatment where the population was logically higher $\left(3.4 \times 10^{5}\right.$ to $\left.4.8 \times 10^{5} \mathrm{CU} / \mathrm{mL}\right)$ due to non-Saccharomyces addition. Total yeast populations were generally stable during the prefermentary stages and reached $7.7 \times 10^{6}$ to $4 \times 10^{7}$ at the beginning of the alcoholic fermentation. A total of 60 colonies per treatment and 180 colonies per stage (4) were isolated from LT medium and subcloning on YPG medium, resulting in 683 clones to be analyzed by MALDI-TOF MS for species identification (Table A4), instead of the 720 planned. Five isolates did not grow after subcloning and only eleven isolates were isolated from one sample, and this sample was therefore not considered for further analyses. Some isolates (26) were not identified as their profiles did not find a match in the database and, finally, 657 isolates $(95 \%)$ were identified successfully at species level by MALDI-TOF MS, among which were ten different species (Figure 5). Metschnikowia pulcherrima, Torulaspora delbrueckii, Aureobasidium pullulans, and Hanseniaspora uvarum were previously reported as OTUs by HTS, whereas Kluyveromyces lactis, Saccharomyces cerevisiae, Whickerhamomyces anomalus, and Lachancea thermotolerans were identified among the "Others". Candida guillermondii and Cryptococcus flavescens were not identified by HTS. As for the Q-PCR analysis, only Metschnikowia pulcherrima was detected with $\mathrm{SO}_{2}$ or without $\mathrm{SO}_{2}(0)$ treatment as part of the indigenous population, with a higher percentage without $\mathrm{SO}_{2}$ at vatting and $24 \mathrm{~h}$ of fermentation $(24 \mathrm{~h})$. 


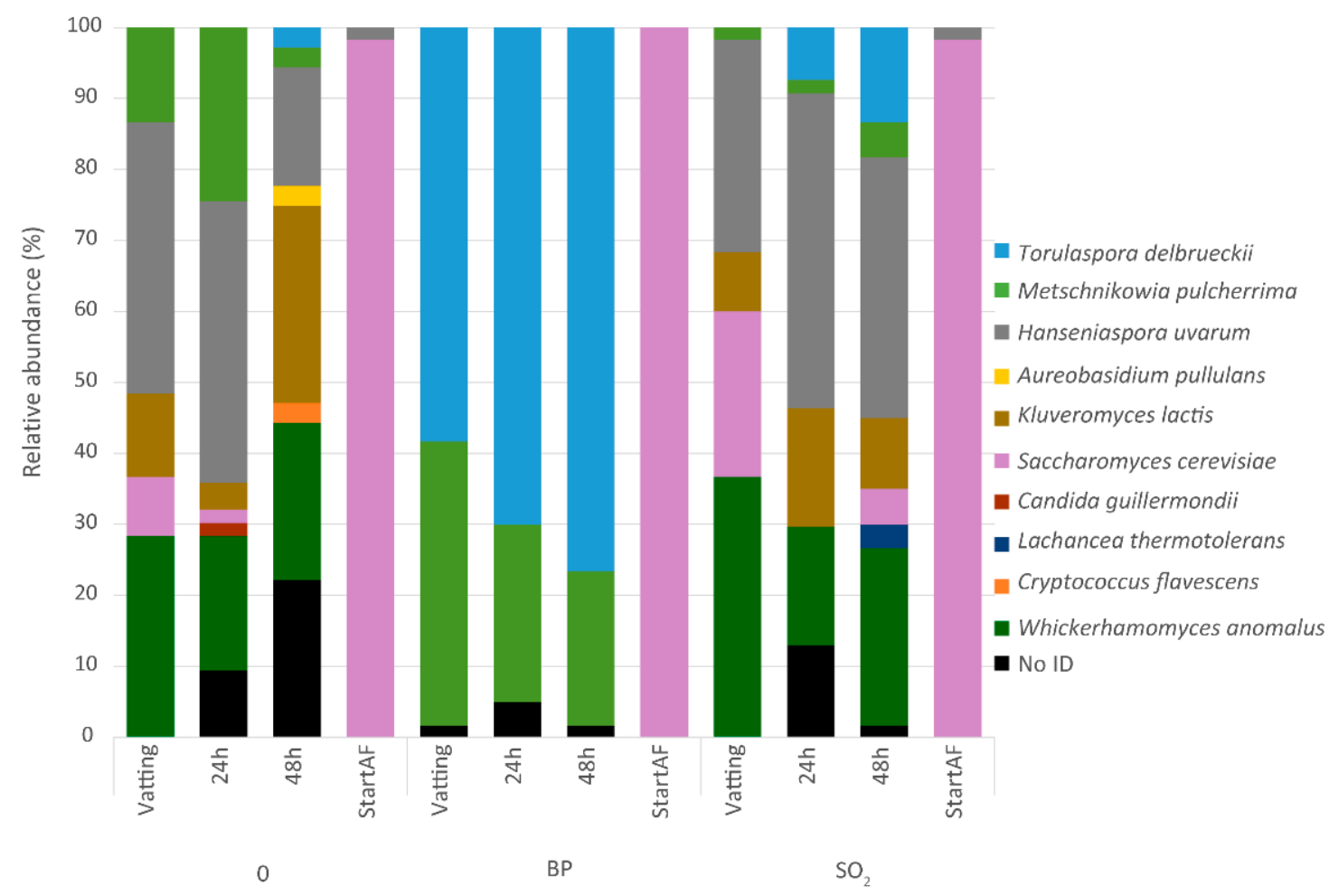

Figure 5. Relative yeast species abundance based on identification by MALDI-TOF MS according to the stages (vatting, $24 \mathrm{~h}, 48 \mathrm{~h}$ of maceration and start of alcoholic fermentation, StartAF) and the modality bioprotection (BP), $\mathrm{SO}_{2}$, and without $\mathrm{SO}_{2}(0)$ treatments.

Concerning bioprotection, $90 \%$ to $100 \%$ of the isolates belonged to the two species Torulaspora delbrueckii and Metschnikowia pulcherrima as expected, whatever the stage considered before the beginning of the alcoholic fermentation. At vatting, Torulaspora delbrueckii and Metschnikowia pulcherrima represented $58 \%$ and $40 \%$ of the total clones, respectively. According to the Q-PCR results, Metschnikowia pulcherrima decreased during prefermentary maceration, unlike Torulaspora delbrueckii for which the percentage of total clones increased (50\% to $90 \%$ after 24 and $48 \mathrm{~h}$ ). Except for bioprotection, Hanseniaspora uvarum, followed by Whickerhamomyces anomalus, were the dominant species during the prefermentary stage. Sulfiting did not result in significant differences in the presence or abundance of other yeast species, except for Metschnikowia pulcherrima, for which the percentage was lower with $\mathrm{SO}_{2}$ addition during the first stage of maceration. As expected, over $98 \%$ of the clones analyzed at the start of AF were identified as S. cerevisiae.

The "Shannon" index was calculated from data obtained by MALDI-TOF MS (Table 3). Bioprotection treatment logically had a significantly lower Shannon index than the others, whatever the stage considered. 
Table 3. Shannon index evaluated by MALDI-TOF MS.

\begin{tabular}{ccc}
\hline \multicolumn{1}{c}{ Stage } & Treatment & Shannon \\
\hline \multirow{1}{*}{ Vatting } & 0 & 1.34 \\
& $\mathrm{SO}_{2}$ & 1.21 \\
& $\mathrm{BP}$ & 0.68 \\
\hline \multirow{3}{*}{$24 \mathrm{~h}$ of maceration } & 0 & 1.24 \\
& $\mathrm{SO}_{2}$ & 1.16 \\
& $\mathrm{BP}$ & 0.52 \\
\hline \multirow{2}{*}{48 h of maceration } & 0 & 1.24 \\
& $\mathrm{SO}_{2}$ & 1.58 \\
0: without any treatment; $\mathrm{SO}_{2}: 50 \mathrm{mg} / \mathrm{L}$ applied in must after crushed; $\mathrm{BP}: 50 \mathrm{mg} / \mathrm{L}$ of bioprotection applied on \\
grapes and without $\mathrm{SO}_{2}$.
\end{tabular}

\section{Discussion}

Until now, yeast diversity analysis by culture-dependent techniques has been performed using 5.8S-ITS-RFLP analysis and/or 26S rDNA D1/D2 domain sequencing [4,6,15,49-51]. This approach based on PCR analysis and DNA sequencing is time-consuming. Recently, MALDI-TOF MS has been demonstrated to be a rapid and cost-effective tool for the identification of wine yeast at the species level $[26,29,33]$. In this study, species identification by MALDI-TOF MS was validated for $66 \%$ of wine yeast isolated at the prefermentary or beginning of alcoholic fermentation stages, in comparison with $26 \mathrm{~S}$ rDNA sequencing. These first results revealed that it was necessary to enrich the MALDI-TOF MS Biotyper database not only with missing wine yeast species, such as Starmerella bacillaris, but also to add wine strains for some species, such as S. cerevisiae or H. uvarum, to improve identification. Different authors $[28,52]$ have already highlighted the importance of enriching the yeast database from standard spectra of isolates originated from the oenological environment. In the present study, the Biotyper database was extended by an oenological laboratory-specific database ( 43 new additional strains corresponding to 17 different species specific to the wine environment). Gutièrrez et al. (2017) [28] reported the successful identification of $95.4 \%$ of yeast isolates after optimization of the preanalytical steps and the development of an in-house MS database. By using standard procedures for colony extraction (without optimization of the preanalytical steps) and an oenological laboratory specific extended data base, we were able to obtain the same identification rate with $95 \%$ of the isolates successfully identified. Our results confirmed that MALDI-TOF MS is a promising and robust method for wine yeast identification at the species level. However, this method does not currently allow differentiation at strain level in the oenological context, especially for Saccharomyces cerevisiae [28,32].

The second aim of the study was to consider a mix of two non-Saccharomyces yeasts as bioprotection (Torulaspora delbrueckii and Metschnikowia pulcherrima) during the prefermentary stages without sulfur dioxide addition at the industrial scale. The MALDI-TOF MS method was used to assess the yeast diversity of the grape juice compared with different commonly-used methods and to monitor the implantation of both bioprotective species.

First, the population dynamics of Torulaspora delbrueckii, Metschnikowia pulcherrima, and Hanseniaspora sp. were analyzed using Q-PCR. By targeting known species in the must ecosystem, this technique has the major advantage of establishing their population dynamics with a low detection level. Its major drawback lies in an overestimation that may be caused by the lack of discrimination between live and dying microorganisms. In the present work, this method allowed us to quantify population levels and to confirm the effective implantation of Torulaspora delbrueckii and Metschnikowia pulcherrima in the bioprotection treatment during the prefermentary stages.

DNA metabarcoding is a method that is increasingly being used to characterize and quantify biodiversity in environmental samples. Illumina metabarcoding generates shorter reads but achieves deeper sequencing than 454 metabarcoding approaches [53]. This 
method also allows quantitative information to be obtained on relative abundances of a genus in particular [54], and biodiversity indices from OTU tables. Numerous studies targeting yeasts and fungi have previously been published [53,55-57]. However, various biases have to be taken into account to interpret the data: (i) as for Q-PCR analysis, grape must may contain many PCR inhibitors [58,59], (ii) taxa with low proportions in a community are underrepresented or have a low amplification reproducibility due to primer mismatches or PCR biases [54,60], (iii) amplified DNA does not provide information as to whether yeast are physiologically active or dead, or may be active within the community. In our study, the most abundant OTUs were assigned to grape fungi, mainly Aureobasidium, Botrytis, and Cladosporium. These OTUs represented more than $75 \%$ of the total abundance, in line with previous results obtained with samples collected in grape must before the start of alcoholic fermentation [9,10]. Grape must yeast diversity in the present study, as reported previously $[19,61,62]$, was quite low compared to other matrices, such as sugar cane or the soil $[53,63,64]$, but nonetheless richer than in traditional sourdoughs [65]. To gain further insight, it would be interesting to use the metagenomic approach to provide a more in-depth understanding, since it offers a non-targeted taxonomic study [66].

Illumina metabarcoding and MALDI-TOF MS allowed concordant yeast identification both at genus and species level, e.g., Aureobasidium, Hanseniaspora, Metschnikowia, and Torulaspora, but with different abundances; Aureobasidium was the most abundant OTU for Illumina metabarcoding, whereas it was detected only in one sample through cultivation, probably due to the use of biphenyl in the cultivation medium (LT). Inverse results were obtained for Hanseniaspora. Saccharomyces was identified among isolates, but with a very low abundance in Illumina data, which is consistent with other studies based on highthroughput sequence analysis, reporting a near-absence of this genus $[1,6,19]$. Microbial culturomics, using multiple culture conditions and MALDI-TOF MS, was successfully applied recently to study human gut microbiota [67] and the plant prokaryotic microbiome [68]. In this study, only one medium was used to target yeasts. Higher combinations of various growth media (for example, specific fungi media) and higher number of isolates analyzed per sample dilution would offer a more in-depth estimation of microbial diversity [69]. Moreover, compared to Illumina metabarcoding, culturomics approaches make it possible to collect colonies related to microbial diversity, thus allowing collection enrichment and further phenotypic analysis.

In oenology, non-Saccharomyces yeast preparations are now proposed as bioprotection agents during the prefermentary stages. However, their impact on the microbial community and antiseptic effectiveness have so far received only a few scientific demonstrations $[14,15]$. Till now, only pure culture of non-Saccharomyces yeast was studied. In the present study, the application of a mix of two species was considered. The ability of both bioprotective species Torulaspora delbrueckii and Metschnikowia pulcherrima to colonize the grape must during prefermentary stages was confirmed by the three methods. However, Metschnikowia pulcherrima decreased during the prefermentary stages, whereas Torulaspora delbrueckii remained stable. The addition of bioprotection led to a decrease in fungal communities, especially Aureobasidium and Botrytis, the latter being considered a common grape pathogen. Hanseniaspora uvarum is a major species in the grape must microbial community, which can have a negative effect on Saccharomyces cerevisiae growth and even lead to delayed alcoholic fermentation [2]. It also produces unwanted metabolites, such as acetic acid, ethyl acetate, sulfur compounds, acetoin, and biogenic amines [70-72]. In this experiment, population levels of Hanseniaspora spp. did not differ between treatments, whatever the prefermentation stage considered, according to the Q-PCR data. No impact of $\mathrm{SO}_{2}$ addition on its relative abundance was shown by either the Illumina or MALDI-TOF MS method, contrary to previous studies that showed lower population levels of Hanseniaspora spp. in the presence of $\mathrm{SO}_{2}$ for white wine vinification [2,17]. However, the species was not identified among clones analyzed from the bioprotection samples by MALDI-TOF MS, suggesting a negative impact of the non-Saccharomyces species on Hanseniaspora uvarum. These results confirmed previous observations by Simonin et al. (2018) [14] who showed 
that the use of Torulaspora delbrueckii as a bioprotection agent on white must (Aligoté) had a negative impact on the development of Hanseniaspora uvarum. Indigenous populations of Metschnikowia pulcherrima were negatively impacted by $\mathrm{SO}_{2}$, according to previous results showing that the growth of this species was affected by the addition of sulfites [15,55]. Metschnikowia pulcherrima populations in the bioprotection modality were also shown to decline, irrespective of the analytical method used. Since no $\mathrm{SO}_{2}$ was added in the bioprotection modality, other factors could explain the population decrease of this species, such as low temperature $\left(13^{\circ} \mathrm{C}\right)$ or negative interaction with Torulaspora delbrueckii.

During maceration, the yeast community was affected more by the stage at which the must was analyzed than by the addition of $\mathrm{SO}_{2}$ or bioprotection. Concerning $\mathrm{SO}_{2}$ addition, a significant impact on the richness in OTUs from the vatting stage to $24 \mathrm{~h}$ of the prefermentary maceration was highlighted, leading to a reduction in the number of OTUs in comparison to the control without $\mathrm{SO}_{2}$. Similar results were also reported on chardonnay, with a significant decrease in the $\alpha$ diversity in the presence of $40 \mathrm{mg} / \mathrm{L} \mathrm{SO}_{2}$ from pressing through to the end of alcoholic fermentation [10]. The diversity indices of Shannon and invSimpson, which take into account the diversity of OTUs and their abundances, were both impacted significantly by the stage, and, to a lesser extent, by the way the different musts were treated. However, additional experiments on different grape musts are needed to confirm our preliminary results.

\section{Conclusions}

In conclusion, the use of the MALDI-TOF MS technique allows yeast biodiversity and the implantation control of both bioprotective non-Saccharomyces yeasts to be assessed quickly and cheaply, thus confirming that it is a robust method for wine yeast identification at species level, despite the high costs of acquiring and maintaining the equipment. In the future, this technique, combined with the use of different selective media allowing cultivation of a large number of clones, should be considered as an interesting alternative to metabarcoding HTS to analyze yeast diversity from grape, must, and wine. The use of $\mathrm{SO}_{2}$ significantly impacts the OTUs diversity, affecting their nature and their abundance. Compared with $\mathrm{SO}_{2}$ modality, bioprotection occupied the niche, leading to a decrease of fungal communities and Hanseniaspora uvarum cultivable population. Additional modalities (with pure culture of Metschnikowia pulcherrima and Torulaspora delbrueckii) are needed to confirm if the use of mix culture of non-Saccharomyces yeast is more efficient than the use of a pure culture one.

Author Contributions: Conceptualization: S.W. and I.M.-P.; methodology: S.W., J.M. and A.V.-C.; investigation: S.W., L.F., L.D., M.L., J.M. and A.V.-C.; formal analysis: S.W.; writing-original draft, S.W., J.M., A.V.-C. and I.M.-P.; writing-review and editing: S.W., J.M., J.C. and I.M.-P.; project administration: I.M.-P.; funding acquisition: I.M.-P. and J.C. All authors have read and agreed to the published version of the manuscript.

Funding: This research received no external funding.

Acknowledgments: The present work was supported by the RESPECT project (Bordeaux Wine council, Nouvelle-Aquitaine region, BioLaffort, and International Organization of Vine and Wine (OIV). We also thank the Technology Transfert Unit Microflora for work on the MALDI-TOF MS technique.

Conflicts of Interest: The authors declare no conflict of interest. 


\section{Appendix A}

Table A1. List of the strains added to the oenological laboratory specific database with GenBank accession number(s).

\begin{tabular}{|c|c|c|c|c|}
\hline Genus & Species & Name CRB & $\begin{array}{c}\text { GenBank Accession } \\
\text { Number(s) }\end{array}$ & $\begin{array}{c}\text { Species Literature } \\
\text { References }\end{array}$ \\
\hline Brettanomyces & acidodurans & NCAIM Y 2178 & & [73] \\
\hline Zygosaccharomyces & bailii & L0536 & MT950295 & [74] \\
\hline Brettanomyces & bruxellensis & CRBO_L0308 & MT950279 & \multirow{15}{*}[46]{} \\
\hline Brettanomyces & bruxellensis & CRBO_L0417 & MT950285 & \\
\hline Brettanomyces & bruxellensis & CRBO_L0422 & MT950286 & \\
\hline Brettanomyces & bruxellensis & CRBO_L0424 & MT950287 & \\
\hline Brettanomyces & bruxellensis & CRBO_L0463 & MT950293 & \\
\hline Brettanomyces & bruxellensis & CRBO_L0512 & MT950294 & \\
\hline Brettanomyces & bruxellensis & CRBO_L0542 & MT950296 & \\
\hline Brettanomyces & bruxellensis & CRBO_L0611 & MT950299 & \\
\hline Brettanomyces & bruxellensis & CRBO_L14156 & MT950310 & \\
\hline Brettanomyces & bruxellensis & CRBO_L14169 & MT950311 & \\
\hline Brettanomyces & bruxellensis & CRBO_L14173 & MT950312 & \\
\hline Brettanomyces & bruxellensis & CRBO_L14195 & MT950313 & \\
\hline Brettanomyces & bruxellensis & CRBO_L1735 & & \\
\hline Brettanomyces & bruxellensis & CRBO_L1750 & & \\
\hline Brettanomyces & bruxellensis & CRBO_L1774 & & \\
\hline Candida & cantarelli & CRBO_L0404 & MT950283 & \\
\hline Candida & cantarelli & CRBO_L0412 & MT950284 & \\
\hline Saccharomyces & cerevisiae & $522 \mathrm{D}$ & & \multirow{5}{*}{ [75] } \\
\hline Saccharomyces & cerevisiae & CRBO_L0431 & MT950288 & \\
\hline Saccharomyces & cerevisiae & CRBO_L0439 & MT950289 & \\
\hline Saccharomyces & cerevisiae & CRBO_L0545 & MT950298 & \\
\hline Saccharomyces & cerevisiae & CRBO_L1117 & MT950308 & \\
\hline Torulaspora & delbrueckii & CRBO_L0544 & МT950297 & \multirow{2}{*}[76]{} \\
\hline Torulaspora & delbrueckii & CRBO_L0630 & MT950300 & \\
\hline Pichia & guiliermondii & CRBO_L0652 & MT950302 & {$[77]$} \\
\hline Shizosaccharomyces & japonicus & Y13611 & & \\
\hline Pichia & kluyveri & CRBO_L0677 & MT950304 & \\
\hline Pichia & membranifaciens & CRBO_L0709 & MT950305 & \\
\hline Schizosaccharomyces & octosporus & Y-8551 & & \\
\hline Schizosaccharomyces & pombe & CRBO_L0442 & MT950290 & \multirow{3}{*}[78]{} \\
\hline Schizosaccharomyces & pombe & CRBO_L0443 & MT950291 & \\
\hline Schizosaccharomyces & pombe & Y12791 & & \\
\hline
\end{tabular}


Table A1. Cont.

\begin{tabular}{|c|c|c|c|c|}
\hline Genus & Species & Name CRB & $\begin{array}{c}\text { GenBank Accession } \\
\text { Number(s) }\end{array}$ & $\begin{array}{c}\text { Species Literature } \\
\text { References }\end{array}$ \\
\hline Metschnikowia & pulcherima & CRBO_L0313 & MT950282 & \multirow{2}{*}{ [79] } \\
\hline Metschnikowia & pulcherima & CRBO_L0640 & MT950301 & \\
\hline Aureobasidium & pullulans & CRBO_L0448 & MT950292 & \multirow{2}{*}{ [80] } \\
\hline Aureobasidium & pullulans & CRBO_L11178 & МТ950309 & \\
\hline Lanchancea & thermotolerans & CRBO_L0672 & MT950303 & [81] \\
\hline Hanseniaspora & uvarum & CRBO_L0312 & MT950281 & \multirow{2}{*}{ [82] } \\
\hline Hanseniaspora & uvarum & CRBO_L0715 & MT950306 & \\
\hline Starmerella & bacillaris & CRBO_L0311 & MT950280 & \multirow{2}{*}{ [83] } \\
\hline Starmerella & bacillaris & CRBO_L0740 & MT950307 & \\
\hline
\end{tabular}

Table A2. Primers used to quantify population levels of microorganisms.

\begin{tabular}{ccc}
\hline Species & Primers & References \\
\hline Metschnikowia pulcherrima & MP2-F AGACACTTAACTGGGCCAGC & [16] \\
MP2-R GGGGTGGTGTGGAAGTAAGG & [7] \\
\hline Torulaspora delbrueckii & TD-F CAAAGTCATCCAAGCCAGC & [7] \\
\hline Hanseniaspora spp. & Hauf 2L-CCCTTTGCCTAAGGTACG & \\
\hline
\end{tabular}

Table A3. Merlot grape must parameters at vatting and wine after alcoholic fermentation analyzed for each modality: $\mathrm{SO}_{2}$ (added $50 \mathrm{mg} / \mathrm{L}$ ), without $\mathrm{SO}_{2}(0)$ and with bioprotection at $50 \mathrm{mg} / \mathrm{L}(\mathrm{BP})$. The analyses were performed according to the official methods described by the European Commission. Values correspond to the average of biological replicates.

\begin{tabular}{ccccccc}
\hline \multicolumn{3}{c}{ Chemical Composition in Must } & \multicolumn{3}{c}{ In Wine } \\
\hline Parameters & $\mathbf{S O}_{\mathbf{2}}$ & $\mathbf{0}$ & $\mathbf{B P}$ & $\mathbf{S O}_{\mathbf{2}}$ & $\mathbf{0}$ & $\mathbf{B P}$ \\
\hline Reducing sugars $(\mathrm{g} / \mathrm{L})$ & 245 & 242 & 243 & 1.0 & 3.0 & 1.4 \\
\hline Total acidity $(\mathrm{g} / \mathrm{L})$ & 1.63 & 1.71 & 1.67 & & & \\
\hline Malic acid (g/L) & 1.1 & 1.0 & 1.1 & & \\
\hline $\mathrm{pH}$ & 3.84 & 3.84 & 3.83 & & \\
\hline $\begin{array}{c}\text { Yeats assimilable nitrogen } \\
\text { (mg/L) }\end{array}$ & 116 & 124 & 111 & & \\
\hline Total $\mathrm{SO}_{2}(\mathrm{mg} / \mathrm{L})$ & 127 & $<10$ & $<10$ & & 0.28 \\
\hline Volatil acidity (acetic acid g/L) & & & & & \\
\hline
\end{tabular}


Table A4. The yeast and fungi diversity of three treatments $\left(\mathrm{SO}_{2}, 0\right.$ and $\left.\mathrm{BP}\right)$ at three stages evaluated by HTS, Q-PCR and MALDI-TOF MS.

\begin{tabular}{|c|c|c|c|c|c|c|c|c|c|c|c|c|c|c|c|c|c|c|c|c|c|c|c|c|c|}
\hline & \multirow{3}{*}{\begin{tabular}{|c|} 
Stage \\
Treatments \\
Duplicats
\end{tabular}} & \multicolumn{6}{|c|}{ 1. Vatting } & \multicolumn{6}{|c|}{ 2. $24 \mathrm{~h}$ of Maceration } & \multicolumn{6}{|c|}{ 3. $48 \mathrm{~h}$ of Maceration } & \multicolumn{6}{|c|}{ 4. Start of $\mathrm{AF}$} \\
\hline & & \multicolumn{2}{|c|}{0} & \multicolumn{2}{|c|}{$\mathrm{SO}_{2}$} & \multicolumn{2}{|c|}{ BP } & \multicolumn{2}{|c|}{0} & \multicolumn{2}{|c|}{$\mathrm{SO}_{2}$} & \multicolumn{2}{|c|}{ BP } & \multicolumn{2}{|c|}{0} & \multicolumn{2}{|c|}{$\mathrm{SO}_{2}$} & \multicolumn{2}{|c|}{ BP } & \multicolumn{2}{|c|}{0} & \multicolumn{2}{|c|}{$\mathrm{SO}_{2}$} & \multicolumn{2}{|c|}{ BP } \\
\hline & & $\mathrm{a}$ & b & $\mathrm{a}$ & $\mathrm{b}$ & $\mathrm{a}$ & $\mathrm{b}$ & $\mathrm{a}$ & $\mathrm{b}$ & $\mathrm{a}$ & $\mathrm{b}$ & $\mathrm{a}$ & b & $\mathrm{a}$ & b & $\mathrm{a}$ & $\mathrm{b}$ & $\mathrm{a}$ & $\mathrm{b}$ & $\mathrm{a}$ & b & $\mathrm{a}$ & $\mathrm{b}$ & $\mathrm{a}$ & b \\
\hline \multirow{10}{*}{ 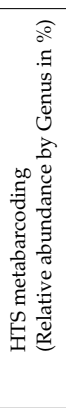 } & Aureobasidium & 63.2 & 48.3 & 49.7 & 50.1 & 20.3 & 20.3 & 49.7 & 50.7 & 41.2 & 30.7 & 13.9 & 26.3 & 46.5 & - & 31.7 & 38.4 & 21.9 & 29.0 & - & - & - & - & - & - \\
\hline & Cladosporium & 18.7 & 20.5 & 20.2 & 22.9 & 7.0 & 6.5 & 18.7 & 20.8 & 24.2 & 26.5 & 10.9 & 6.9 & 16.6 & - & 17.0 & 15.9 & 7.1 & 16.3 & - & - & - & - & - & - \\
\hline & Botrytis & 11.1 & 20.4 & 15.8 & 14.5 & 3.6 & 3.9 & 17.7 & 16.8 & 15.1 & 14.5 & 8.7 & 4.3 & 13.4 & - & 16.4 & 19.7 & 9.2 & 7.8 & - & - & - & - & - & - \\
\hline & Alternaria & 0.6 & 1.9 & 1.6 & 2.3 & 0.8 & 1.0 & 1.5 & 2.1 & 5.2 & 1.6 & 1.5 & 2.2 & - & - & 4.3 & 2.6 & 2.6 & 1.3 & - & - & - & - & - & - \\
\hline & Diplodia & 0.9 & 1.6 & 2.0 & 2.0 & 0.6 & 0.4 & 2.0 & 2.7 & 0.1 & 2.9 & 0.1 & 0.9 & 0.9 & - & 1.4 & 6.2 & 1.1 & 0.7 & - & - & - & - & - & - \\
\hline & Torulaspora & 0.3 & 0.2 & 2.7 & 0.4 & 24.8 & 26.6 & 0.5 & 0.2 & 4.0 & 3.0 & 33.4 & 24.0 & 5.5 & - & 7.5 & 7.7 & 24.1 & 25.2 & - & - & - & - & - & - \\
\hline & Metschnikowia & 0.1 & 0.2 & 0.1 & 0.1 & 40.5 & 39.0 & 0.3 & 0.2 & 5.7 & 0.1 & 29.4 & 31.7 & 0.1 & - & 0.0 & 0.1 & 27.3 & 16.2 & - & - & - & - & - & - \\
\hline & Hanseniaspora & 0.4 & 0.5 & 1.2 & 0.7 & 0.1 & 0.1 & 3.8 & 0.1 & 0.2 & 2.0 & 0.1 & 0.1 & 2.4 & - & 0.2 & 0.2 & 0.2 & 1.9 & - & - & - & - & - & - \\
\hline & $\begin{array}{c}\text { unknown } \\
\text { genus }\end{array}$ & 1.1 & 1.4 & 1.9 & 1.7 & 0.5 & 0.5 & 1.1 & 1.4 & 1.0 & 0.0 & 0.0 & 0.5 & 4.9 & - & 1.3 & 0.0 & 1.6 & 0.1 & - & - & - & - & - & - \\
\hline & others & 1.7 & 1.4 & 1.9 & 2.5 & $\begin{array}{ll}0.8 \\
\end{array}$ & 0.6 & 1.7 & 1.7 & 0.8 & 5.8 & 0.2 & 1.4 & 1.9 & - & 3.1 & 1.0 & 0.8 & 0.8 & - & - & - & - & - & - \\
\hline \multirow{3}{*}{ 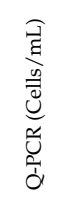 } & $\begin{array}{l}\text { Torulaspora } \\
\text { delbrueckii }\end{array}$ & $<100$ & $<100$ & $<100$ & $<100$ & $\begin{array}{l}4.5 \times \\
10^{4}\end{array}$ & $\begin{array}{c}6.8 \times \\
10^{4}\end{array}$ & $<100$ & $<100$ & $<100$ & $<100$ & $\begin{array}{l}1.2 \times \\
106\end{array}$ & $\begin{array}{l}4.8 \times \\
105\end{array}$ & $<100$ & $<100$ & $<100$ & $<100$ & $\begin{array}{c}7.7 \times \\
10^{4}\end{array}$ & $\begin{array}{l}1.1 \times \\
10^{5}\end{array}$ & $\begin{array}{l}3.7 \times \\
10^{2}\end{array}$ & $\begin{array}{l}4.6 \times \\
10^{2}\end{array}$ & $\begin{array}{l}8.8 \times \\
10^{2}\end{array}$ & $\begin{array}{l}2.9 \times \\
10^{2}\end{array}$ & $\begin{array}{c}1.2 \times \\
10^{4}\end{array}$ & $\begin{array}{l}4.8 \times \\
10^{5}\end{array}$ \\
\hline & $\begin{array}{c}\text { Metschnikowia } \\
\text { pulcherrima }\end{array}$ & $\begin{array}{l}3.9 \times \\
10^{2}\end{array}$ & $\begin{array}{c}5.8 \times \\
10^{2}\end{array}$ & $<100$ & $<100$ & $\begin{array}{c}4.5 \times \\
10^{6}\end{array}$ & $\begin{array}{c}4.3 \times \\
10^{6}\end{array}$ & $<100$ & $<100$ & $<100$ & $<100$ & $\begin{array}{l}1.6 \times \\
106\end{array}$ & $\begin{array}{l}8.4 \times \\
105\end{array}$ & $<100$ & $<100$ & $\begin{array}{c}1.1 \times \\
10^{2}\end{array}$ & $<100$ & $\begin{array}{c}3.8 \times \\
10^{4}\end{array}$ & $\begin{array}{l}2.9 \times \\
10^{4}\end{array}$ & $\begin{array}{l}2.0 \times \\
10^{2}\end{array}$ & $\begin{array}{l}1.3 \times \\
10^{4}\end{array}$ & $<100$ & $<100$ & $\begin{array}{c}1.6 \times \\
10^{6}\end{array}$ & $\begin{array}{c}8.4 \times \\
10^{5}\end{array}$ \\
\hline & $\begin{array}{l}\text { Hanseniaspora } \\
\text { sp. }\end{array}$ & $\begin{array}{c}9.2 \times \\
10^{3}\end{array}$ & $\begin{array}{r}5.4 \times \\
10^{3}\end{array}$ & $\begin{array}{c}1.2 \times \\
10^{4}\end{array}$ & $\begin{array}{c}4.6 \times \\
10^{3}\end{array}$ & $\begin{array}{c}5.2 \times \\
10^{3}\end{array}$ & $\begin{array}{c}6.7 \times \\
10^{3}\end{array}$ & $\begin{array}{c}7.4 \times \\
10^{3}\end{array}$ & $\begin{array}{l}2.1 \times \\
10^{3}\end{array}$ & $\begin{array}{c}2.3 \times \\
10^{3}\end{array}$ & $\begin{array}{c}2.0 \times \times \\
10^{3}\end{array}$ & $\begin{array}{c}2.1 \times \\
10^{3}\end{array}$ & $\begin{array}{l}2.0 \times \\
10^{3}\end{array}$ & $\begin{array}{c}2.9 \times \\
10^{2}\end{array}$ & $\begin{array}{c}2.1 \times \times \\
10^{3}\end{array}$ & $\begin{array}{c}2.8 \times \\
10^{2}\end{array}$ & $\begin{array}{c}2.4 \times \\
10^{3}\end{array}$ & $\begin{array}{c}3.4 \times \\
10^{2}\end{array}$ & $\begin{array}{c}2.7 \times \\
10^{3}\end{array}$ & $\begin{array}{c}2.8 \times \\
10^{5}\end{array}$ & $\begin{array}{c}1.1 \times \\
10^{6}\end{array}$ & $\begin{array}{c}1.2 \times \\
10^{6}\end{array}$ & $\begin{array}{l}3.4 \times \\
10^{5}\end{array}$ & $\begin{array}{c}3.6 \times \\
10^{5}\end{array}$ & $\begin{array}{c}1.4 \times \\
10^{5}\end{array}$ \\
\hline
\end{tabular}


Table A4. Cont.

\begin{tabular}{|c|c|c|c|c|c|c|c|c|c|c|c|c|c|c|c|c|c|c|c|c|c|c|c|c|c|}
\hline & \multirow{3}{*}{\begin{tabular}{|c|} 
Stage \\
Treatments \\
Duplicats \\
\end{tabular}} & \multicolumn{6}{|c|}{ 1. Vatting } & \multicolumn{6}{|c|}{ 2. $24 \mathrm{~h}$ of Maceration } & \multicolumn{6}{|c|}{ 3. $48 \mathrm{~h}$ of Maceration } & \multicolumn{6}{|c|}{ 4. Start of $\mathrm{AF}$} \\
\hline & & \multicolumn{2}{|c|}{0} & \multicolumn{2}{|c|}{$\mathrm{SO}_{2}$} & \multicolumn{2}{|c|}{ BP } & \multicolumn{2}{|c|}{0} & \multicolumn{2}{|c|}{$\mathrm{SO}_{2}$} & \multicolumn{2}{|c|}{ BP } & \multicolumn{2}{|c|}{0} & \multicolumn{2}{|c|}{$\mathrm{SO}_{2}$} & \multicolumn{2}{|c|}{ BP } & \multicolumn{2}{|c|}{0} & \multicolumn{2}{|c|}{$\mathrm{SO}_{2}$} & \multicolumn{2}{|c|}{ BP } \\
\hline & & $\mathbf{a}$ & b & $\mathbf{a}$ & $\mathbf{b}$ & $\mathbf{a}$ & $\mathbf{b}$ & $\mathbf{a}$ & $\mathbf{b}$ & $\mathrm{a}$ & b & $a$ & $\mathbf{b}$ & $\mathbf{a}$ & $\mathbf{b}$ & $\mathrm{a}$ & b & $\mathbf{a}$ & $\mathbf{b}$ & $\mathbf{a}$ & $\mathbf{b}$ & $\mathbf{a}$ & $\mathbf{b}$ & $\mathbf{a}$ & $\mathbf{b}$ \\
\hline \multirow{11}{*}{ 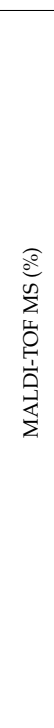 } & $\begin{array}{c}\text { TOTAL } \\
\text { number of } \\
\text { colonies } \\
\text { analyzed }\end{array}$ & 30 & 30 & 30 & 30 & 30 & 30 & 23 & 30 & 24 & 30 & 30 & 30 & 30 & 6 & 30 & 30 & 30 & 30 & 30 & 30 & 30 & 30 & 30 & 30 \\
\hline & $\begin{array}{c}\text { Torulaspora } \\
\text { delbruekii }\end{array}$ & - & - & - & - & 56.7 & 60.0 & - & - & 4.2 & 10.0 & 90.0 & 50.0 & 3.3 & - & 16.7 & 10.0 & 86.7 & 66.7 & - & - & - & - & - & - \\
\hline & $\begin{array}{c}\text { Metschnikowia } \\
\text { pulcherrima }\end{array}$ & - & 26.7 & - & 3.3 & 40.0 & 40.0 & 13.0 & 33.3 & - & 3.3 & 10.0 & 40.0 & 3.3 & 16.7 & 3.3 & 6.7 & 10.0 & 33.3 & - & - & - & - & - & - \\
\hline & $\begin{array}{c}\text { Hanseniaspora } \\
\text { uvarum }\end{array}$ & 40.0 & 36.7 & 13.3 & 46.7 & - & - & 34.8 & 43.3 & 58.3 & 33.3 & - & - & 16.7 & - & 43.3 & 30.0 & - & - & 3.0 & - & 3.0 & - & - & - \\
\hline & $\begin{array}{c}\text { Aureobasidium } \\
\text { pullulans }\end{array}$ & - & - & - & - & - & - & - & - & - & - & - & - & - & - & - & - & - & - & - & - & - & - & - & - \\
\hline & $\begin{array}{c}\text { Kluveromyces } \\
\text { lactis }\end{array}$ & 13.3 & 10.0 & 3.3 & 13.3 & - & - & 8.7 & - & 12.5 & 20.0 & - & - & 33.3 & - & 10.0 & 10.0 & - & - & - & - & - & - & - & - \\
\hline & $\begin{array}{c}\text { Saccharomyces } \\
\text { cerevisiae }\end{array}$ & 13.3 & 3.3 & 36.7 & 10.0 & - & - & 4.3 & - & - & - & - & - & - & - & - & 10.0 & - & - & 97 & 100 & 97 & 100 & 100 & 100 \\
\hline & $\begin{array}{c}\text { Candida } \\
\text { guillermondii }\end{array}$ & - & - & - & - & - & - & 4.3 & - & - & - & - & - & - & 16.7 & - & - & - & - & - & - & - & - & - & - \\
\hline & $\begin{array}{c}\text { Lachancea } \\
\text { thermotolerans }\end{array}$ & - & - & - & - & - & - & - & - & - & - & - & - & - & 16.7 & 3.3 & 3.3 & - & - & - & - & - & - & - & - \\
\hline & $\begin{array}{c}\text { Cryptococcus } \\
\text { flavescens }\end{array}$ & - & - & - & - & - & - & - & - & - & - & - & - & - & - & - & - & - & - & - & - & - & - & - & - \\
\hline & No ID & - & - & - & - & 3.3 & - & 13.0 & 6.7 & 12.5 & 13.3 & - & 10.0 & 16.7 & 50.0 & - & 3.3 & 3.3 & - & - & - & - & - & - & - \\
\hline
\end{tabular}




\section{References}

1. Bokulich, N.A.; Thorngate, J.H.; Richardson, P.M.; Mills, D.A. PNAS Plus: From the Cover: Microbial biogeography of wine grapes is conditioned by cultivar, vintage, and climate. Proc. Nat. Acad. Sci. USA 2014, 111, E139-E148. [CrossRef]

2. Albertin, W.; Miot-Sertier, C.; Bely, M.; Marullo, P.; Coulon, J.; Moine, V.; Colonna-Ceccaldi, B.; Masneuf-Pomarede, I. Oenological prefermentation practices strongly impact yeast population dynamics and alcoholic fermentation kinetics in Chardonnay grape must. Int. J. Food Microbiol. 2014, 178, 87-97. [CrossRef] [PubMed]

3. Chasseriaud, L.; Coulon, J.; Marullo, P.; Albertin, W.; Bely, M. New oenological practice to promote non-Saccharomyces species of interest: Saturating grape juice with carbon dioxide. Appl. Microbiol. Biotechnol. 2018, 102, 3779-3791. [CrossRef]

4. Zott, K.; Miot-Sertier, C.; Claisse, O.; Lonvaud-Funel, A.; Masneuf-Pomarede, I. Dynamics and diversity of non-Saccharomyces yeasts during the early stages in winemaking. Int. J. Food Microbiol. 2008, 125, 197-203. [CrossRef]

5. Lleixà, J.; Manzano, M.; Mas, A.; Portillo, M.D.C. Saccharomyces and non-Saccharomyces Competition during Microvinification under Different Sugar and Nitrogen Conditions. Front. Microbiol. 2016, 7, 1959. [CrossRef] [PubMed]

6. Wang, C.; García-Fernández, D.; Mas, A.; Esteve-Zarzoso, B. Fungal diversity in grape must and wine fermentation assessed by massive sequencing, quantitative PCR and DGGE. Front. Microbiol. 2015, 6, 1156. [CrossRef] [PubMed]

7. Zott, K.; Claisse, O.; Lucas, P.; Coulon, J.; Lonvaud-Funel, A.; Masneuf-Pomarede, I. Characterization of the yeast ecosystem in grape must and wine using real-time PCR. Food Microbiol. 2010, 27, 559-567. [CrossRef] [PubMed]

8. Bokulich, N.A.; Swadener, M.; Sakamoto, K.; Mills, D.A.; Bisson, L.F. Sulfur Dioxide Treatment Alters Wine Microbial Diversity and Fermentation Progression in a Dose-Dependent Fashion. Am. J. Enol. Vitic. 2014, 66, 73-79. [CrossRef]

9. Morgan, S.C.; McCarthy, G.C.; Watters, B.S.; Tantikachornkiat, M.; Zigg, I.; Cliff, M.A.; Durall, D.M. Effect of sulfite addition and pied de cuve inoculation on the microbial communities and sensory profiles of Chardonnay wines: Dominance of indigenous Saccharomyces uvarum at a commercial winery. FEMS Yeast Res. 2019, 19, 49. [CrossRef]

10. Morgan, S.C.; Tantikachornkiat, M.; Scholl, C.M.; Benson, N.L.; Cliff, M.A.; Durall, D.M. The effect of sulfur dioxide addition at crush on the fungal and bacterial communities and the sensory attributes of Pinot gris wines. Int. J. Food Microbiol. 2019, 290, 1-14. [CrossRef]

11. Constantí, M.; Reguant, C.; Poblet, M.; Zamora, F.; Mas, A.; Guillamón, J.M. Molecular Analysis of Yeast Population Dynamics: Effect of Sulphur Dioxide and Inoculum on Must Fermentation. Int. J. Food Microbiol. 1998, 41, 169-175. [CrossRef]

12. Henick-Kling, T.; Edinger, W.; Daniel, P.; Monk, P. Selective Effects of Sulfur Dioxide and Yeast Starter Culture Addition on Indigenous Yeast Populations and Sensory Characteristics of Wine. J. Appl. Microbiol. 1998, 84, 865-876. [CrossRef]

13. Morgan, S.C.; Scholl, C.M.; Benson, N.L.; Stone, M.L.; Durall, D.M. Sulfur dioxide addition at crush alters Saccharomyces cerevisiae strain composition in spontaneous fermentations at two Canadian wineries. Int. J. Food Microbiol. 2017, 244, 96-102. [CrossRef]

14. Simonin, S.; Alexandre, H.; Nikolantonaki, M.; Coelho, C.; Tourdot-Maréchal, R. Inoculation of Torulaspora delbrueckii as a bio-protection agent in winemaking. Food Res. Int. 2018, 107, 451-461. [CrossRef]

15. Simonin, S.; Roullier-Gall, C.; Ballester, J.; Schmitt-Kopplin, P.; Quintanilla-Casas, B.; Vichi, S.; Peyron, D.; Alexandre, H.; Tourdot-Maréchal, R. Bio-Protection as an Alternative to Sulphites: Impact on Chemical and Microbial Characteristics of Red Wines. Front. Microbiol. 2020, 11, 1308. [CrossRef] [PubMed]

16. García, M.; Esteve-Zarzoso, B.; Crespo, J.; Cabellos, J.M.; Arroyo, T. Yeast Monitoring of Wine Mixed or Sequential Fermentations Made by Native Strains from D.O. “Vinos de Madrid" Using Real-Time Quantitative PCR. Front. Microbiol. 2017, 8, 2520. [CrossRef]

17. Andorrà, I.; Landi, S.; Mas, A.; Guillamón, J.M.; Esteve-Zarzoso, B. Effect of Oenological Practices on Microbial Populations Using Culture-Independent Techniques. Food Microbiol. 2008, 25, 849-856. [CrossRef] [PubMed]

18. Sirén, K.; Mak, S.S.T.; Fischer, U.; Hansen, L.H.; Gilbert, M.T.P. Multi-omics and potential applications in wine production. Curr. Opin. Biotechnol. 2019, 56, 172-178. [CrossRef]

19. David, V.; Terrat, S.; Herzine, K.; Claisse, O.; Rousseaux, S.; Tourdot-Maréchal, R.; Masneuf-Pomarede, I.; Ranjard, L.; Alexandre, $\mathrm{H}$. High-throughput sequencing of amplicons for monitoring yeast biodiversity in must and during alcoholic fermentation. J. Ind. Microbiol. Biotechnol. 2014, 41, 811-821. [CrossRef]

20. Pinto, C.; Pinho, D.; Cardoso, R.; Custódio, V.; Fernandes, J.P.; Sousa, S.; Pinheiro, M.; Egas, C.; Gomes, A.C. Wine fermentation microbiome: A landscape from different Portuguese wine appellations. Front. Microbiol. 2015, 6, 905. [CrossRef]

21. Heather, J.M.; Chain, B. The sequence of sequencers: The history of sequencing DNA. Genomics 2016, 107, 1-8. [CrossRef] [PubMed]

22. Clark, A.E.; Kaleta, E.J.; Arora, A.; Wolk, D.M. Matrix-Assisted Laser Desorption Ionization-Time of Flight Mass Spectrometry: A Fundamental Shift in the Routine Practice of Clinical Microbiology. Clin. Microbiol. Rev. 2013, 26, 547-603. [CrossRef] [PubMed]

23. Ferroni, A.; Suarez, S.; Beretti, J.-L.; Dauphin, B.; Bille, E.; Meyer, J.; Bougnoux, M.-E.; Alanio, A.; Berche, P.; Nassif, X. RealTime Identification of Bacteria and Candida Species in Positive Blood Culture Broths by Matrix-Assisted Laser Desorption Ionization-Time of Flight Mass Spectrometry. J. Clin. Microbiol. 2010, 48, 1542-1548. [CrossRef]

24. Akimowicz, M.; Bucka-Kolendo, J. MALDI-TOF MS-Application in Food Microbiology. Acta Biochim. Pol. 2020, 67, 327-332. [CrossRef] 
25. Turvey, M.E.; Weiland, F.; Meneses, J.; Sterenberg, N.; Hoffmann, P. Identification of beer spoilage microorganisms using the MALDI Biotyper platform. Appl. Microbiol. Biotechnol. 2016, 100, 2761-2773. [CrossRef] [PubMed]

26. Usbeck, J.C.; Kern, C.C.; Vogel, R.F.; Behr, J. Optimization of experimental and modelling parameters for the differentiation of beverage spoiling yeasts by Matrix-Assisted-Laser-Desorption/Ionization-Time-of-Flight Mass Spectrometry (MALDI-TOF MS) in response to varying growth conditions. Food Microbiol. 2013, 36, 379-387. [CrossRef] [PubMed]

27. Wieme, A.D.; Spitaels, F.; Aerts, M.; De Bruyne, K.; Van Landschoot, A.; Vandamme, P. Identification of beer-spoilage bacteria using matrix-assisted laser desorption/ionization time-of-flight mass spectrometry. Int. J. Food Microbiol. 2014, 185, 41-50. [CrossRef]

28. Gutiérrez, C.; Flechoso, M.D.L.; Ángeles, G.; Belda, I.; Ruiz, J.; Kayali, N.; Polo, L.; Santos, A. Wine yeasts identification by MALDI-TOF MS: Optimization of the preanalytical steps and development of an extensible open-source platform for processing and analysis of an in-house MS database. Int. J. Food Microbiol. 2017, 254, 1-10. [CrossRef] [PubMed]

29. Zhang, J.; Plowman, J.E.; Tian, B.; Clerens, S.; On, S.L. An improved method for MALDI-TOF analysis of wine-associated yeasts. J. Microbiol. Methods 2020, 172, 105904. [CrossRef] [PubMed]

30. Blättel, V.; Petri, A.; Rabenstein, A.; Kuever, J.; König, H. Differentiation of species of the genus Saccharomyces using biomolecular fingerprinting methods. Appl. Microbiol. Biotechnol. 2013, 97, 4597-4606. [CrossRef] [PubMed]

31. Moothoo-Padayachie, A.; Kandappa, H.R.; Krishna, S.B.N.; Maier, T.; Govender, P. Biotyping Saccharomyces cerevisiae strains using matrix-assisted laser desorption/ionization time-of-flight mass spectrometry (MALDI-TOF MS). Eur. Food Res. Technol. 2013, 236, 351-364. [CrossRef]

32. Usbeck, J.C.; Wilde, C.; Bertrand, D.; Behr, J.; Vogel, R.F. Wine yeast typing by MALDI-TOF MS. Appl. Microbiol. Biotechnol. 2014, 98, 3737-3752. [CrossRef] [PubMed]

33. Kačániová, M.; Kunova, S.; Felsöciová, S.; Ivanišová, E.; Kántor, A.; Puchalski, C.; Terentjeva, M. Microbiota of different wine grape berries. Potravin. Slovak J. Food Sci. 2019, 13, 174-181. [CrossRef]

34. Du Plessis, H.; Du Toit, M.; Hoff, J.; Hart, R.; Ndimba, B.; Jolly, N. Characterisation of Non-Saccharomyces Yeasts Using Different Methodologies and Evaluation of their Compatibility with Malolactic Fermentation. S. Afr. J. Enol. Vitic. 2017, 38, 46-63. [CrossRef]

35. Lücke, F.-K. Utilization of microbes to process and preserve meat. Meat Sci. 2000, 56, 105-115. [CrossRef]

36. Stiles, M.E. Biopreservation by lactic acid bacteria. Antonie Leeuwenhoek 1996, 70, 331-345. [CrossRef]

37. Kurtzman, C.P.; Robnett, C.J. Identification of clinically important ascomycetous yeasts based on nucleotide divergence in the $5^{\prime}$ end of the large-subunit (26S) ribosomal DNA gene. J. Clin. Microbiol. 1997, 35, 1216-1223. [CrossRef]

38. Pavlovic, M.; Mewes, A.; Maggipinto, M.; Schmidt, W.; Messelhäußer, U.; Balsliemke, J.; Hörmansdorfer, S.; Busch, U.; Huber, I. MALDI-TOF MS Based Identification of Food-Borne Yeast Isolates. J. Microbiol. Methods 2014, 106, 123-128. [CrossRef] [PubMed]

39. Bilecen, K.; Yaman, G.; Ciftci, U.; Laleli, Y.R. Performances and Reliability of Bruker Microflex LT and VITEK MS MALDI-TOF Mass Spectrometry Systems for the Identification of Clinical Microorganisms. BioMed Res. Int. 2015, 2015, 1-18. [CrossRef]

40. Condina, M.R.; Dilmetz, B.A.; Bazaz, S.R.; Meneses, J.; Warkiani, M.E.; Hoffmann, P. Rapid separation and identification of beer spoilage bacteria by inertial microfluidics and MALDI-TOF mass spectrometry. Lab Chip 2019, 19, 1961-1970. [CrossRef] [PubMed]

41. Escudié, F.; Auer, L.; Bernard, M.; Mariadassou, M.; Cauquil, L.; Vidal, K.; Maman, S.; Hernandez-Raquet, G.; Combes, S.; Pascal, G. FROGS: Find, Rapidly, OTUs with Galaxy Solution. Bioinformatics 2018, 34, 1287-1294. [CrossRef]

42. Mahé, F.; Rognes, T.; Quince, C.; De Vargas, C.; Dunthorn, M. Swarm v2: Highly-scalable and high-resolution amplicon clustering. PeerJ 2015, 3, e1420. [CrossRef] [PubMed]

43. Rognes, T.; Flouri, T.; Nichols, B.; Quince, C.; Mahé, F. VSEARCH: A versatile open source tool for metagenomics. PeerJ 2016, 4, e2584. [CrossRef] [PubMed]

44. Quast, C.; Pruesse, E.; Yilmaz, P.; Gerken, J.; Schweer, T.; Yarza, P.; Peplies, J.; Glöckner, F.O. The SILVA Ribosomal RNA Gene Database Project: Improved Data Processing and Web-Based Tools. Nucleic Acids Res. 2012, 41, D590-D596. [CrossRef] [PubMed]

45. McMurdie, P.J.; Holmes, S. phyloseq: An R Package for Reproducible Interactive Analysis and Graphics of Microbiome Census Data. PLoS ONE 2013, 8, e61217. [CrossRef] [PubMed]

46. Avramova, M.; Cibrario, A.; Peltier, E.; Coton, M.; Coton, E.; Schacherer, J.; Spano, G.; Capozzi, V.; Blaiotta, G.; Salin, F.; et al. Brettanomyces bruxellensis population survey reveals a diploid-triploid complex structured according to substrate of isolation and geographical distribution. Sci. Rep. 2018, 8, 1-13. [CrossRef]

47. Barata, A.; Malfeito-Ferreira, M.; Loureiro, V. The microbial ecology of wine grape berries. Int. J. Food Microbiol. 2012, 153, 243-259. [CrossRef]

48. Martins, G.M. Communautés Microbiennes de La Baie de Raisin: Incidence Des Facteurs Biotiques et Abiotiques: Incidence Des Facteurs Biotiques et Abiotiques. Communautés Microbiennes de la Baie de Raisin: Incidence des Facteurs Biotiques et Abiotiques. Ph.D. Thesis, Université de Bordeaux Ségalen, Bordeaux, France, 2012.

49. Esteve-Zarzoso, B.; Belloch, C.; Uruburu, F.; Querol, A. Identification of yeasts by RFLP analysis of the 5.8S rRNA gene and the two ribosomal internal transcribed spacers. Int. J. Syst. Evol. Microbiol. 1999, 49, 329-337. [CrossRef]

50. Granchi, L.; Bosco, M.; Messini, A.; Vincenzini, M. Rapid detection and quantification of yeast species during spontaneous wine fermentation by PCR-RFLP analysis of the rDNA ITS region. J. Appl. Microbiol. 1999, 87, 949-956. [CrossRef] 
51. Prakitchaiwattana, C.J.; Fleet, G.H.; Heard, G.M. Application and evaluation of denaturing gradient gel electrophoresis to analyse the yeast ecology of wine grapes. FEMS Yeast Res. 2004, 4, 865-877. [CrossRef] [PubMed]

52. Agustini, B.C.; Silva, L.P.; Bloch, C.; Bonfim, T.M.B.; Da Silva, G.A. Evaluation of MALDI-TOF mass spectrometry for identification of environmental yeasts and development of supplementary database. Appl. Microbiol. Biotechnol. 2014, 98, 5645-5654. [CrossRef] [PubMed]

53. Schmidt, P.-A.; Bálint, M.; Greshake, B.; Bandow, C.; Römbke, J.; Schmitt, I. Illumina metabarcoding of a soil fungal community. Soil Biol. Biochem. 2013, 65, 128-132. [CrossRef]

54. Leray, M.; Knowlton, N. Random sampling causes the low reproducibility of rare eukaryotic OTUs in Illumina COI metabarcoding. PeerJ 2017, 5, e3006. [CrossRef]

55. Bagheri, B.; Bauer, F.F.; Cardinali, G.; Setati, M.E. Ecological interactions are a primary driver of population dynamics in wine yeast microbiota during fermentation. Sci. Rep. 2020, 10, 1-12. [CrossRef]

56. Colabella, C.; Corte, L.; Roscini, L.; Bassetti, M.; Tascini, C.; Mellor, J.C.; Meyer, W.; Robert, V.; Vu, D.; Cardinali, G. NGS barcode sequencing in taxonomy and diagnostics, an application in "Candida" pathogenic yeasts with a metagenomic perspective. IMA Fungus 2018, 9, 91-105. [CrossRef]

57. Stefanini, I.; Cavalieri, D. Metagenomic Approaches to Investigate the Contribution of the Vineyard Environment to the Quality of Wine Fermentation: Potentials and Difficulties. Front. Microbiol. 2018, 9, 991. [CrossRef] [PubMed]

58. Işçi, B.; Yıldırım, H.K.; Altindişli, A. Evaluation of methods for DNA extraction from must and wine. J. Inst. Brew. 2014, 120, 238-243. [CrossRef]

59. Belda, I.; Zarraonaindia, I.; Perisin, M.; Palacios, A.; Acedo, A. From Vineyard Soil to Wine Fermentation: Microbiome Approximations to Explain the "Terroir" Concept. Front. Microbiol. 2017, 8, 821. [CrossRef]

60. Gonzalez, J.M.; Portillo, M.C.; Belda-Ferre, P.; Mira, A. Amplification by PCR Artificially Reduces the Proportion of the Rare Biosphere in Microbial Communities. PLoS ONE 2012, 7, e29973. [CrossRef]

61. Bokulich, N.A.; Collins, T.S.; Masarweh, C.; Allen, G.; Heymann, H.; Ebeler, S.E.; Mills, D.A. Associations among Wine Grape Microbiome, Metabolome, and Fermentation Behavior Suggest Microbial Contribution to Regional Wine Characteristics. $m B i o$ 2016, 7, e00631-16. [CrossRef]

62. Boynton, P.J.; Greig, D. Species richness influences wine ecosystem function through a dominant species. Fungal Ecol. 2016, 22, 61-72. [CrossRef]

63. De Souza, R.S.C.; Okura, V.K.; Armanhi, J.S.L.; Jorrín, B.; Lozano, N.; Da Silva, M.J.; González-Guerrero, M.; De Araújo, L.M.; Verza, N.C.; Bagheri, H.C.; et al. Unlocking the bacterial and fungal communities assemblages of sugarcane microbiome. Sci. Rep. 2016, 6, 1-15. [CrossRef] [PubMed]

64. Brinkmann, N.; Schneider, D.; Sahner, J.; Ballauff, J.; Edy, N.; Barus, H.; Irawan, B.; Budi, S.W.; Qaim, M.; Daniel, R.; et al. Intensive tropical land use massively shifts soil fungal communities. Sci. Rep. 2019, 9, 1-11. [CrossRef]

65. Minervini, F.; Lattanzi, A.; De Angelis, M.; Celano, G.; Gobbetti, M. House microbiotas as sources of lactic acid bacteria and yeasts in traditional Italian sourdoughs. Food Microbiol. 2015, 52, 66-76. [CrossRef] [PubMed]

66. Sirén, K.; Mak, S.S.T.; Melkonian, C.; Carøe, C.; Swiegers, J.H.; Molenaar, D.; Fischer, U.; Gilbert, M.T.P. Taxonomic and Functional Characterization of the Microbial Community During Spontaneous in vitro Fermentation of Riesling Must. Front. Microbiol. 2019, 10, 697. [CrossRef]

67. Lagier, J.-C.; Khelaifia, S.; Alou, M.T.; Ndongo, S.; Dione, N.; Hugon, P.; Caputo, A.; Cadoret, F.; Traore, S.I.; Seck, E.H.; et al. Culture of previously uncultured members of the human gut microbiota by culturomics. Nat. Microbiol. 2016, 1, 1-8. [CrossRef]

68. Sarhan, M.S.; Hamza, M.A.; Youssef, H.H.; Patz, S.; Becker, M.; ElSawey, H.; Nemr, R.; Daanaa, H.-S.A.; Mourad, E.F.; Morsi, A.T.; et al. Culturomics of the plant prokaryotic microbiome and the dawn of plant-based culture media-A review. J. Adv. Res. 2019, 19, 15-27. [CrossRef]

69. Mourad, E.F.; Sarhan, M.; Daanaa, H.-S.A.; Abdou, M.; Morsi, A.T.; Abdelfadeel, M.R.; Elsawey, H.; Nemr, R.; El-Tahan, M.; Hamza, M.A.; et al. Plant Materials are Sustainable Substrates Supporting New Technologies of Plant-Only-Based Culture Media for in vitro Culturing of the Plant Microbiota. Microbes Environ. 2018, 33, 40-49. [CrossRef]

70. Ciani, M.; Picciotti, G. The growth kinetics and fermentation behaviour of some non-Saccharomyces yeasts associated with wine-making. Biotechnol. Lett. 1995, 17, 1247-1250. [CrossRef]

71. Comi, G.; Romano, P.; Cocolin, L.; Fiore, C. Characterization of Kloeckera apiculata strains from the Friuli regionin Northern Italy. World J. Microbiol. Biotechnol. 2001, 17, 391-394. [CrossRef]

72. Romano, P.; Fiore, C.; Paraggio, M.; Caruso, M.; Capece, A. Function of Yeast Species and Strains in Wine Flavour. Int. J. Food Microbiol. 2003, 86, 169-180. [CrossRef]

73. Péter, G.; Dlauchy, D.; Tóbiás, A.; Fülöp, L.; Podgoršek, M.; Čadež, N. Brettanomyces Acidodurans Sp. Nov., a New Acetic Acid Producing Yeast Species from Olive Oil. Antonie Leeuwenhoek 2017, 110, 657-664. [CrossRef]

74. Schuller, D.; Côrte-Real, M.; Leão, C. A Differential Medium for the Enumeration of the Spoilage Yeast Zygosaccharomyces Bailii in Wine. J. Food Prot. 2000, 63, 1570-1575. [CrossRef] [PubMed]

75. Börlin, M.; Venet, P.; Claisse, O.; Salin, F.; Legras, J.-L.; Masneuf-Pomarede, I. Cellar-Associated Saccharomyces Cerevisiae Population Structure Revealed High-Level Diversity and Perennial Persistence at Sauternes Wine Estates. Appl. Environ. Microbiol. 2016, 82, 2909-2918. [CrossRef] [PubMed] 
76. Albertin, W.; Chasseriaud, L.; Comte, G.; Panfili, A.; Delcamp, A.; Salin, F.; Marullo, P.; Bely, M. Winemaking and Bioprocesses Strongly Shaped the Genetic Diversity of the Ubiquitous Yeast Torulaspora Delbrueckii. PLoS ONE 2014, 9, e94246. [CrossRef]

77. Jensen, S.L.; Umiker, N.L.; Arneborg, N.; Edwards, C.G. Identification and Characterization of Dekkera Bruxellensis, Candida Pararugosa, and Pichia Guilliermondii Isolated from Commercial Red Wines. Food Microbiol. 2009, 26, 915-921. [CrossRef] [PubMed]

78. Benito, Á.; Jeffares, D.; Palomero, F.; Calderón, F.; Bai, F.-Y.; Bähler, J.; Benito, S. Selected Schizosaccharomyces Pombe Strains Have Characteristics That Are Beneficial for Winemaking. PLoS ONE 2016, 11, e0151102. [CrossRef] [PubMed]

79. Oro, L.; Ciani, M.; Comitini, F. Antimicrobial Activity of M Etschnikowia Pulcherrima on Wine Yeasts. J. Appl. Microbiol. 2014, 116, 1209-1217. [CrossRef]

80. Onetto, C.A.; Borneman, A.R.; Schmidt, S.A. Investigating the Effects of Aureobasidium Pullulans on Grape Juice Composition and Fermentation. Food Microbiol. 2020, 90, 103451. [CrossRef]

81. Hranilovic, A.; Gambetta, J.M.; Schmidtke, L.; Boss, P.K.; Grbin, P.R.; Masneuf-Pomarede, I.; Bely, M.; Albertin, W.; Jiranek, V. Oenological Traits of Lachancea Thermotolerans Show Signs of Domestication and Allopatric Differentiation. Sci. Rep. 2018, 8, 14812. [CrossRef]

82. Albertin, W.; Setati, M.E.; Miot-Sertier, C.; Mostert, T.T.; Colonna-Ceccaldi, B.; Coulon, J.; Girard, P.; Moine, V.; Pillet, M.; Salin, F.; et al. Hanseniaspora Uvarum from Winemaking Environments Show Spatial and Temporal Genetic Clustering. Front. Microbiol. 2016, 6. [CrossRef] [PubMed]

83. Englezos, V.; Giacosa, S.; Rantsiou, K.; Rolle, L.; Cocolin, L. Starmerella Bacillaris in Winemaking: Opportunities and Risks. Curr. Opin. Food Sci. 2017, 17, 30-35. [CrossRef] 